\title{
ANÁLISE EMPÍRICA DA FORMAÇÃO DE EXPECTATIVAS DE INFLAÇÃO NO BRASIL: UMA APLICAÇÃO DE REDES NEURAIS ARTIFICIAIS A DADOS EM PAINEL*
}

\author{
Andreza Aparecida Palma ${ }^{* *}$
}

Marcelo Savino Portugal ${ }^{* * *}$

\begin{abstract}
RESUMO O objetivo principal deste trabalho é estudar empiricamente o processo de formação de expectativas inflacionárias no Brasil, no período recente (pós-metas de inflação), através de um modelo conexionista, que aproxima a forma como os agentes fazem previsões. Os resultados obtidos permitem afirmar que a maior influência sobre as expectativas inflacionárias no período como um todo foi da volatilidade cambial, seguida pela variação no preço das commodities, pela defasagem de ordem um das expectativas, pela variação cambial e pela meta. Em menor magnitude, afetam as expectativas o resultado primário do governo, a defasagem de ordem dois e a taxa Selic. No período de crise de confiança, há um expressivo descolamento das expectativas em relação à meta, com um aumento do efeito das demais variáveis. Resultado inverso ocorre no período pós-crise: o efeito da meta de inflação aumenta e o das demais variáveis tende a se reduzir, ainda que em alguns casos tais efeitos sejam expressivos (como da defasagem de ordem um e da volatilidade cambial). Isso permite concluir que o Banco Central vem consolidando sua credibilidade ao longo do tempo, mas que há ainda espaço para melhorias.
\end{abstract}

Palavras-chave: expectativas inflacionárias; metas de inflação; redes neurais artificiais; bootstrap; dados em painel

Código JEL: C23; C45; E52

* Artigo recebido em 24 de abril de 2008 e aprovado em 10 de agosto de 2009.

** Doutoranda em Economia do Programa de Pós-graduação em Economia na Universidade Federal do Rio Grande do Sul, e-mail: drepalma@gmail.com

*** Professor titular da UFRGS e pesquisador do CNPq do Programa de Pós-graduação em Economia, e-mail:msp@ufrgs.br 


\section{EMPIRICAL ANALYSIS OF THE FORMATION \\ OF INFLATIONARY EXPECTATIONS IN BRAZIL:}

AN APPLICATION OF ARTIFICIAL NEURAL

NETWORKS TO PANEL DATA

ABSTRACT This work aims to empirically study the formation process of inflationary expectations in Brazil, in the recent period (after the introduction of the inflation targeting policy) by a connexionist model that approaches the way agents forecast. The coordination of market expectations in relation to the future inflation is a crucial aspect of the inflation targeting. The results obtained allow us to affirm that the biggest influence on the inflationary expectations in the period as a whole was from exchange rate volatility, followed by the commodities prices variation, by the first order lag of the expectations, by the exchange rate variation and by the target. In lesser magnitude, the primary result of the government, the second order lag and the Selic tax affect the expectations. In the period of reliable crisis, there is an expressive shift of the expectations in relation to the target, with an increase of the effect of the other variables. Inverse result occurs in the aftercrisis period: the effect of the inflation target increases and of the other variables tend to be reduced, despite in some cases such effect are expressive (as the first order lag and exchange rate volatility). Thus we may conclude that the Brazilian Central Bank has been consolidating its credibility throughout the time, but there is still an open space for improvements.

Key words: inflation expectations; inflation targeting; artificial neural networks; bootstrap; panel data 


\section{INTRODUÇÃO}

$\mathrm{Na}$ ciência econômica, as expectativas dos agentes a respeito dos valores futuros das variáveis são de fundamental importância. É a presença de variáveis expectacionais uma das características que distingue os modelos econômicos dos modelos matemáticos usados em ciências naturais. De fato, a teoria econômica moderna reconhece que a diferença central entre a economia e as ciências naturais está nas decisões "forward-looking" feitas pelos agentes econômicos (Evans e Honkapohja, 2001, p. 5). ${ }^{1}$ Além disso, de acordo com a crítica de Lucas (1976), mudanças na política econômica alteram as expectativas dos agentes. Essas mudanças, por sua vez, alteram os parâmetros dos modelos econômicos. Assim, entender como se dá o processo de formação de expectativas é de fundamental importância na modelagem econômica. E esse é um importante desafio para os economistas: compreenderem como as pessoas interpretam o mundo e formam as expectativas que irão influenciar variáveis econômicas relevantes.

De maneira mais específica, em um país que adota o regime de metas de inflação, as expectativas dos agentes em relação à inflação futura exercem um papel de grande destaque. Altas taxas de inflação alimentam expectativas futuras de inflação mais elevada. Para ancorar essas expectativas, a autoridade monetária se compromete a conter a inflação dentro dos intervalos da meta previamente anunciados. Se a autoridade monetária conta com grande credibilidade, não existe razão para esperar uma taxa de inflação mais alta no futuro, mesmo se a inflação for elevada no período atual. Assim, a autoridade monetária tem a missão de conduzir a sua política de forma a atingir o nível de preços previamente estabelecido, forçando a convergência das expectativas inflacionárias para a meta. Como resultado, o regime de metas de inflação enfraquece a ligação entre a inflação realizada e a inflação passada, com a variável expectacional tomando um papel de grande destaque para o funcionamento adequado do regime. Quando a política monetária perde credibilidade, o Banco Central aumenta a taxa de juros a fim de controlar a inflação. Pode-se dizer, assim, que o aspecto fundamental do regime de metas de inflação é a coordenação das expectativas dos agentes.

Ao longo do desenvolvimento da teoria econômica, foram assumidas algumas regras de formação para as expectativas: estáticas (naive expecta- 
tions), extrapolativas, adaptativas e racionais. O conceito de expectativas racionais foi introduzido por Muth (1961) e é a suposição dominante em macroeconomia. Tal conceito estabelece que os agentes formam suas expectativas eficientemente com base em toda a informação relevante disponível, ou seja, os agentes não cometem erros sistemáticos em suas previsões. ${ }^{2}$ Apesar de largamente utilizado, tal processo de formação de expectativas tem sido bastante questionado, pois assume que os agentes não apenas usam toda a sua informação de maneira ótima, mas também que possuem toda a informação requerida para a previsão. Tais hipóteses são muito restritivas, pois implicam que os agentes no modelo tenham mais conhecimento que o próprio econometrista que o estima (Sargent, 1993). Assim, uma maneira mais apropriada para modelar a formação de expectativas seria supor que os agentes no modelo agem, eles próprios, da forma como trabalha um econometrista ou um estatístico. ${ }^{3}$

Seguindo essa abordagem, o uso de redes neurais artificiais (RNAs) se mostra uma ferramenta bastante apropriada para a modelagem de expectativas. A análise de regressão paramétrica clássica, que é a ferramenta mais utilizada em econometria para verificar relações entre variáveis, bem como para fazer previsões, possui algumas limitações, como, por exemplo, a necessidade de se assumir uma distribuição de probabilidade para os dados e uma forma funcional para a relação entre as variáveis. No processo de formação de expectativas, é inadequado assumir que isso seja de conhecimento dos agentes, visto que, geralmente, não é de conhecimento dos próprios economistas. Os modelos de RNAs possuem a característica atraente de reconhecer trajetórias altamente complexas (não lineares) sem que se especifique a forma funcional dessa relação, ou seja, podem ser considerados como aproximadores universais. ${ }^{4}$ Modelando a formação de expectativas com o uso de RNAs, tenta-se aproximar a maneira pela qual os agentes formam suas previsões. ${ }^{5}$

Uma das desvantagens frequentemente citadas das RNAs e que limitava seu maior uso em análises empíricas como a proposta no presente trabalho era a não existência de métodos que permitissem a realização de inferência estatística formal com esses modelos. Racine e White (2001) apresentaram uma contribuição particular para o problema de inferência em RNAs: um método baseado nas derivadas parciais da rede que utiliza a técnica de boots- 
trap para obter a distribuição dos estimadores. Dessa forma, podemos realizar testes de hipóteses a respeito da significância individual e conjunta das variáveis de entrada (inputs) da RNA. O método, contudo, é aplicável apenas no contexto de dados i.i.d. Uma solução possível para a aplicação dessa metodologia no caso de dados dependentes é o uso do bootstrap em bloco. Como se utiliza um painel de dados com dependência temporal e possível ausência de dependência espacial, para a realização da inferência é sugerida a utilização do bootstrap apenas nas unidades cross-section, conforme Kapetanios (2004). A atratividade desse procedimento é que ele permite a aplicação do bootstrap para dados i.i.d. em vez da aplicação do bootstrap em bloco que, como salientam Lahiri (2003) e Andrews (2002), tem fornecido aproximações menos acuradas que o bootstrap padrão.

Dado o exposto, o objetivo principal do presente trabalho é estudar empiricamente a formação de expectativas inflacionárias no Brasil no período recente (pós-metas de inflação). O principal diferencial em relação aos trabalhos anteriores está na metodologia empregada: a modelagem através de RNAs. Além disso, os dados utilizados também são distintos, já que aqui se empregam como variável dependente as expectativas para o IPCA acumulado em 12 meses de cada instituição em cada ponto no tempo, constituindo um painel de dados não balanceado. Os estudos anteriores usavam alguma medida agregada, tal como a média ou mediana do mês ou então os dados diários (como foi o caso de Yoshihiro (2005)). A principal motivação para o uso do painel de dados foi a reduzida amostra que se teria utilizando os dados agregados. Além disso, como bem salientado por Hsiao (2005), a utilização de dados em painel permite uma maior capacidade para capturar a complexidade do comportamento humano, quando comparado a séries de tempo ou cross-section simples.

O restante deste trabalho está organizado como segue. A seção 1 faz uma discussão sobre o papel das expectativas inflacionárias no regime de metas de inflação, além de revisar a literatura empírica para o caso brasileiro a respeito da formação de expectativas nesse regime. A seção 2 expõe brevemente algumas considerações sobre RNAs e econometria. Na seção 3, é discutida a utilização dos modelos de RNAs no caso de dados em painel e, a seção 4, apresenta a metodologia para inferência estatística em tais modelos proposta por Racine e White (2001) para dados i.i.d. e duas modificações 
sugeridas para o caso de dados dependentes: o bootstrap em bloco e, para o caso de dados em painel com ausência de dependência espacial, a reamostragem apenas na dimensão transversal. A seção 5 apresenta a análise empírica e a seção 6 , os comentários finais.

\section{EXPECTATIVAS DE INFLAÇÃO E O REGIME DE METAS DE INFLAÇÃO}

O regime de metas de inflação foi adotado pioneiramente na Nova Zelândia, em 1990, e, no Brasil, em junho de 1999. A característica principal desse regime é o anúncio de metas a serem cumpridas para determinado indicador de inflação. Essa é a informação básica a ser divulgada para o setor privado como um todo. A implementação do regime de metas de inflação envolve a definição e divulgação oficial de limites para um dado índice de inflação em determinado horizonte de tempo. Assim, a autoridade monetária tem a missão de conduzir a sua política de forma a atingir o nível de preços previamente estabelecido, forçando a convergência das expectativas inflacionárias dos agentes econômicos para a meta. Como resultado, o regime de metas de inflação enfraquece a ligação entre a inflação realizada e a inflação esperada, com a variável expectacional tomando um papel de grande destaque para o funcionamento adequado do regime.

O regime de metas de inflação pode ser visualizado como a avaliação por parte da autoridade monetária de uma função objetivo, na qual tanto a estabilização da inflação quanto do produto são importantes:

$$
L_{t}=E_{t-1} \sum_{i=0}^{\infty} \beta^{i}\left[\left(\pi_{t+i}-\pi^{m e t a}\right)^{2}+\lambda x_{t+i}^{2}\right]
$$

onde:

$\pi^{\text {meta }}=$ meta de inflação

$\lambda=$ peso dado ao hiato do produto

O objetivo da autoridade monetária é escolher a taxa de juros $i_{t}$ (instrumento de política monetária) que minimiza a função perda acima. ${ }^{6} \mathrm{E}$ a escolha de $i_{t}$ está sujeita às restrições representadas pelas equações a seguir: 


$$
\begin{aligned}
& E_{t-1} x_{t}=E_{t-1} x_{t+1}-\frac{1}{\sigma}\left(i_{t}-E_{t-1} \pi_{t+1}\right) \\
& E_{t-1} \pi_{t}=\beta E_{t-1} \pi_{t+1}+\kappa E_{t-1} x_{t}+\rho e_{t-1}
\end{aligned}
$$

A condição de primeira ordem para a escolha de $i_{t}$ implica: ${ }^{7}$

$$
E_{t-1} x_{t}=-\left(\frac{\kappa}{\lambda}\right) E_{t-1}\left(\pi_{t}-\pi^{m e t a}\right)
$$

A previsão da inflação, portanto, é um elemento crucial no regime de metas de inflação, pois ela é quem guiará as decisões da política monetária. Se a previsão de inflação da autoridade monetária para o período $t$ exceder a meta, a política deve ser ajustada de forma a assegurar que a previsão do hiato do produto seja negativa. Dessa forma, a política monetária é forward-looking, estando preocupada com a inflação esperada, e não com a inflação corrente e, assim, respondendo às pressões inflacionárias que possam afetar o alcance da meta previamente estabelecida. Essa característica constitui a principal diferença entre o regime de metas de inflação e os demais regimes monetários.

\subsection{Estudos empíricos sobre a formação de expectativas}

inflacionárias no regime de metas de inflação: o caso brasileiro

O processo de formação de expectativas no Brasil tem recebido uma atenção maior no período recente, devido à implementação do sistema de metas de inflação em junho de 1999, no qual as expectativas inflacionárias têm um papel central, como vimos. Desde então, o Banco Central do Brasil vem coletando diariamente as expectativas do mercado a respeito das principais variáveis macroeconômicas. ${ }^{8}$ Com esse banco de dados, é possível realizar estudos empíricos sobre a formação de expectativas no Brasil, ainda que de forma limitada, dado o tamanho reduzido da amostra.

Esses estudos têm como objetivo central verificar o papel exercido pela meta de inflação na formação de expectativas, controlando para outros determinantes. Se o coeficiente dessa variável for estatisticamente significativo e próximo de um, teremos evidências de que a política monetária é crível. 
Os estudos realizados para o período utilizam como variável dependente a expectativa de mercado para o IPCA 12 meses à frente e têm como principal método de estimação o de mínimos quadrados ordinários, em um contexto de regressão linear univariada para séries temporais. Foge a essa regra de metodologia o estudo de Mello e Moccero (2006), o qual utiliza um framework multivariado. As evidências apresentadas, em geral, apontam para o forte papel exercido pela meta de inflação sobre as expectativas, no período como um todo. Quando é utilizada a estimação recursiva, o comportamento observado é de influência crescente da meta e decrescente das demais variáveis. Entretanto, quando a amostra inclui o período de crise de confiança (eleições de 2002), os resultados apontam para um descolamento das expectativas em relação à meta e uma influência maior das demais variáveis durante a crise. Dessa forma, os estudos sugerem que a política monetária vem consolidando a sua credibilidade ao longo do tempo e que caminha na direção certa. Em uma abordagem distinta, contudo, Lowenkron e Garcia (2007) mostram que, no Brasil, a surpresa de curto prazo da inflação afeta o desvio das expectativas em relação à meta, o que seria evidência da falta de credibilidade, contrariamente aos demais trabalhos.

Os primeiros estudos, que utilizaram uma amostra mais reduzida, são descritos a seguir. Minella et al. (2002) analisaram o período de 2000-2001 a 2002-2006, usando como variáveis explicativas lags de ordem 1 e 2 das expectativas, a meta de inflação 12 meses à frente e a taxa de juros. Os coeficientes dessas variáveis foram todos estatisticamente significantes a $5 \% \mathrm{e}$ com o sinal esperado. O resultado mais importante foi o coeficiente da meta de inflação, estimado em 0,96 , mostrando que as expectativas reagem de forma significativa à meta. ${ }^{9}$

Schmidt-Hebbel e Werner (2002) realizaram um estudo para o Brasil, México e Chile. Aqui nos deteremos a descrever apenas os resultados encontrados para o Brasil, que é foco do presente trabalho. Os regressores utilizados foram a depreciação da taxa nominal de câmbio, a diferença entre a inflação e a sua expectativa, o desvio da inflação esperada em relação à meta $\mathrm{e}$ a diferença da inflação em relação ao seu núcleo, para o período de 19992012 a 2001-2010. Os resultados indicaram que apenas o desvio da inflação em relação à meta é significante para o caso do Brasil. Os autores concluem, com isso, que a meta de inflação exerce uma influência forte e credível nas 
expectativas do setor privado. Utilizando a técnica de estimação recursiva, os autores mostram que o coeficiente da taxa de depreciação do câmbio declina de forma constante ao longo do período, enquanto o coeficiente da meta de inflação é positivo, grande, estatisticamente significante e relativamente estável; o coeficiente da inflação não antecipada é próximo de zero durante todo o período, bem como a diferença entre o núcleo e a inflação cheia.

Minella et al. (2003) basicamente atualizam o estudo realizado por Minella et al. (2002), utilizando o período 2000-2001 a 2003-2002. Através do método dos MQO, os autores encontram que a expectativa de inflação 12 meses à frente é influenciada por seus lags (de primeira e segunda ordem), pela meta de inflação (12 meses), pela taxa de juros e pela taxa de inflação de 12 meses. O coeficiente da meta estimado é, novamente, próximo de 1, o que seria uma evidência forte de que as metas têm um papel importante na formação de expectativas dos agentes. Utilizando estimação recursiva, os autores também encontram que o coeficiente do termo de inflação passada começou a aumentar a partir do final de 2001 (o que seria explicado pelos choques significantes que afetaram a economia) e, mais expressivamente, nos últimos meses de 2002 e início de 2003, o que seria reflexo da crise de confiança nesse período. De fato, com a amostra finalizando em setembro de 2002, o coeficiente do termo de inflação passada é insignificante. Foram adicionadas também as variáveis Embi Plus e variação da taxa de câmbio em 12 meses, esta última não se mostrando estatisticamente significante. Para a amostra finalizando em setembro de 2002, o risco-Brasil também não é significante.

Com um grande conjunto de variáveis, selecionadas posteriormente pela análise de componentes principais, Carvalho e Bugarin (2005) estudaram empiricamente a formação de expectativas inflacionárias no Brasil, no período de junho 1999 a novembro de 2003, utilizando a inflação esperada 12 meses à frente. ${ }^{10}$ Os resultados mostram que, no período anterior a 2002, o coeficiente da meta inflacionária do Bacen era altamente significante e próximo de 1, mostrando alta credibilidade da política monetária. Analisando a amostra após novembro de 2002, os autores encontram um comportamento adaptativo forte na formação de expectativas inflacionárias. Além disso, nesse período, a meta de inflação do Bacen deixa de ser estatisticamente significante. 
Para um período um pouco maior e em uma abordagem parecida com dos estudos citados, Cerisola e Gelos (2005) também investigam os principais determinantes macroeconômicos das expectativas inflacionárias no Brasil, tendo como diferencial a inclusão de variáveis fiscais entre os regressores. O modelo inclui como variáveis explicativas das expectativas o lag de ordem 1 da taxa de inflação de 12 meses, a meta de inflação de 12 meses, superavit primário consolidado (\% PIB) com defasagem de um trimestre, taxa de juros real com três meses de defasagem, desvios da taxa de câmbio efetiva real e do salário real de seus valores históricos, também defasados em um trimestre. Os resultados obtidos sugerem que o regime de metas de inflação tem sido eficiente em ancorar as expectativas. A estimação recursiva evidencia que desde 2003, e especialmente durante 2004, as expectativas têm sido crescentemente ancoradas pela meta de inflação e menos dependentes da inflação passada. A política fiscal se mostrou importante instrumento para ancorar as expectativas, especialmente durante os períodos de elevada incerteza (como em 2002).

O estudo mais recente é o de Bevilaqua, Mesquita e Minella (2007), para o período de 2000-2001 a 2006-2008. Eles encontram evidências do papel crítico exercido pela meta como atratora das expectativas inflacionárias. Contudo, tomando o período da crise de confiança em meados de 2002 e início de 2003, o coeficiente da meta é bastante baixo ou não significante, dependendo da versão do modelo utilizada, ocorrendo o contrário para o período mais recente. Quanto ao comportamento dos demais coeficientes dos modelos apresentados, os autores ressaltam dois resultados mais importantes em relação ao período recente. O primeiro é que o efeito da taxa de câmbio é mais baixo ou até não significante, o que indicaria uma possível redução do pass-through na economia. E o segundo é que o coeficiente da inflação passada é próximo de 0 e não significante. Com a inclusão do risco-Brasil, a inflação defasada deixa de ser significante. Como ressaltado pelos autores, a presença de regressores estatisticamente significantes além da meta de inflação não é um indício de falta de credibilidade do Banco Central, mas, sim, de quão rico e complexo é o mecanismo de transmissão. Dessa forma, mesmo autoridades monetárias com credibilidade alta não são capazes de eliminar completamente as flutuações da inflação.

De maneira distinta dos trabalhos citados, Yoshihiro (2005) utiliza os dados diários e as expectativas em primeira diferença, já que os testes de raiz 
unitária apontaram para a não estacionariedade dessa série. $\mathrm{O}$ autor verifica a influência da variação cambial nominal, nível de IGP-M atual, preço do petróleo futuro, IPCA atual, meta de inflação 12 meses, do Embi Brasil e da crise eleitoral de 2002 sobre as expectativas do IPCA 12 meses à frente, ${ }^{11}$ durante o período de novembro de 2001 a março de 2005. O preço do petróleo futuro, o risco-Brasil, o IPCA e o IGPM não se mostraram estatisticamente significantes. A meta de inflação foi significante estatisticamente e com coeficiente positivo, refletindo que atua como guia para a formação de expectativas dos agentes (o coeficiente estimado foi de 0,76 ). Ao contrário dos estudos anteriores, a variação cambial se mostrou estatisticamente significante para o período como um todo. A fim de analisar a evolução dos coeficientes ao longo do tempo, os autores realizaram o mesmo exercício a três subperíodos: 2002, 2002-2003 e 2002-2004. A conclusão do trabalho é que a credibilidade da política monetária ainda está incompleta, mas caminha na direção correta.

Através da análise de cointegração, Mello e Moccero (2006) estimam a função de reação do Banco Central e os determinantes da inflação esperada no Brasil, Chile, Colômbia e México. O objetivo principal é avaliar a presença de comovimentos de longo prazo entre a taxa de juros, a meta de inflação e as expectativas inflacionárias. Os autores também testaram a presença de spillovers $^{12}$ de volatilidade entre a taxa de juros (instrumento de política monetária) e as expectativas de inflação, através dos modelos M-Garch. No caso brasileiro, para o período de 2001:07 a 2006:1, seus resultados apontam que, a longo prazo, as expectativas têm sido influenciadas pelas metas de inflação e taxa de juros (ou seja, as expectativas têm sido efetivamente ancoradas). Além disso, uma maior volatilidade da taxa de juros leva a maior volatilidade das expectativas de inflação, concluindo que uma suavização nas mudanças do instrumento de política monetária ajudaria a reduzir a volatilidade das expectativas de inflação.

Em uma abordagem também distinta dos demais estudos, Lowenkron e Garcia (2006) verificam o efeito de surpresas de curto prazo nas expectativas de inflação de médio prazo no Brasil, comparando os resultados com outros países do mundo. Para tanto, é estimado um modelo em que a variável dependente é o desvio da meta de 12 meses $\left(I P C A_{12 m}^{e}-M E T A_{12 m}^{\text {Bacen }}\right)$ e as variáveis explicativas consistem na primeira defasagem da variável de- 
pendente, na surpresa inflacionária de curto prazo $\left(I P C A_{t}-\left.I P C A_{\mathrm{t}}^{e}\right|_{t-1}\right) \mathrm{e}$ na variação do câmbio. A principal conclusão dos autores é que as surpresas de inflação de curto prazo induzem uma variação significativa nas expectativas dos agentes, mesmo "expurgando" o efeito da taxa de câmbio. O mais interessante é que o Brasil seria um dos poucos países em que as surpresas de curto prazo da inflação afetam as expectativas de médio prazo. Segundo os autores, isso seria um sintoma de um de dois possíveis problemas: inércia inflacionária causada pela indexação da economia e/ou falta de credibilidade da política monetária. $\mathrm{O}$ modelo desenvolvido ${ }^{13}$ afirma que a falta de credibilidade pode ser verificada através do comportamento dos comovimentos no prêmio de risco da inflação. ${ }^{14}$ Essa análise mostra que essa é uma das causas no Brasil, ${ }^{15}$ já que foi encontrada uma forte relação entre as surpresas de inflação de curto prazo e o prêmio de risco da inflação.

\section{REDES NEURAIS ARTIFICIAIS E ECONOMETRIA}

As RNAs originaram-se da tentativa de imitar o funcionamento do cérebro humano para criar um modelo que possuísse características peculiares deste, tais como a robustez e tolerância a falhas, flexibilidade, capacidade de aprendizagem, processamento paralelo de informação e grande habilidade para reconhecer trajetórias (Abelém, A. J. G. 1994, p. 9; Misra e Warner, 1996, p. 2). Apesar da origem, as RNAs estão muito distantes das redes neurais biológicas e podem, de fato, ser vistas como modelos estatísticos. As ligações dos modelos de RNAs com os modelos econométricos, por exemplo, são bem grandes. Na tabela 1, apresentamos um pequeno dicionário de alguns termos utilizados em RNAs e seus correspondentes em estatística.

Tabela 1: Redes neurais $\times$ econometria

\begin{tabular}{ll}
\hline Redes neurais & Econometria \\
\hline Pesos & Parâmetros \\
\hline Conjunto de treinamento & Amostra \\
\hline Entradas & Variáveis independentes/explicativas \\
\hline Saídas/produtos & Valor estimado da variável dependente \\
\hline Alvos & Variáveis dependentes/endógenas \\
\hline Retropropagação & Aproximação estocástica \\
\hline Treinamento/aprendizado & Estimação \\
\hline Fonte: Adaptado de Fernandes, Portugal e Navaux (1996, p. 257). &
\end{tabular}


A construção de uma RNA é equivalente à construção de uma fórmula matemática, só que de forma gráfica (Deboeck, 1994, p. 4). O funcionamento de um modelo neural consiste, basicamente, em, dados os valores de entrada (inputs), ajustar os pesos de forma que estes produzam o resultado desejado. A figura $1^{16}$ mostra uma RNA (ou seja, uma "fórmula gráfica") para o caso de uma regressão linear múltipla.

As entradas $X_{i}$ da RNA correspondem às variáveis explicativas do modelo de regressão linear múltipla, os pesos $a_{i}$, aos coeficientes que devem ser estimados e o produto $(\mathrm{Y})$, aos valores estimados. Dessa forma, uma RNA de camada única, com função de ativação linear, é análoga a um modelo de regressão linear múltipla.

Uma RNA de camada única com mais de um produto pode ser equivalente a um modelo VAR (vetor autorregressivo), se os dados forem séries

Figura 1: Exemplo de RNA para uma regressão linear múltipla

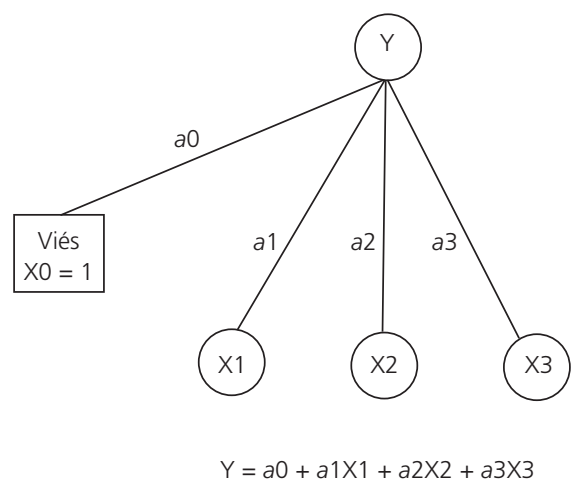

Figura 2: RNA com dois produtos

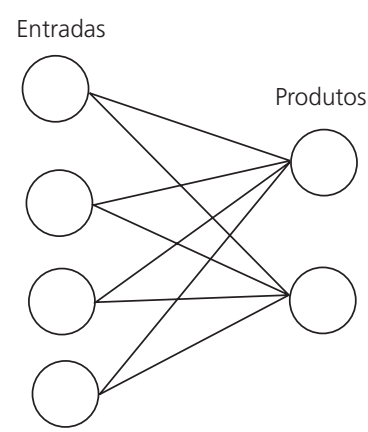


temporais. Ou, introduzindo os próprios alvos como variáveis de entrada (tomando o cuidado, obviamente, de não fazer a conexão de uma variável com ela mesma), obtém-se uma RNA equivalente a um sistema de equações simultâneas.

Uma RNA de camada única com função de ativação não linear também tem o seu correspondente em econometria. Considere que, na figura 1, a função de ativação seja a logística. O produto da rede, nesse caso, estará limitado a assumir valores entre 0 e 1 . A rede resultante é, dessa forma, equivalente ao modelo logit. E se a função de ativação for a função densidade de probabilidade normal acumulada, tem-se o conhecido modelo Probit (ou Normit). E usando outras funções limitadas, serão obtidas redes equivalentes a modelos econométricos que se aplicam a variáveis dependentes limitadas.

O poder computacional das RNAs em trabalhar com problemas complexos está na inclusão de camadas de neurônios intermediários entre as entradas e a camada de saída. As RNAs com uma camada oculta são as mais utilizadas em problemas de previsão. Existem trabalhos teóricos que mostram que uma camada oculta é suficiente para aproximar qualquer função não linear complexa (ver, por exemplo, Hornik et al., 1989), desde que se tenha um número suficiente de neurônios. Como se mostra a seguir, uma RNA desse tipo pode ser visualizada como uma regressão não linear. Seja $\left\{\left(x_{i t}\right.\right.$, $\left.\left.y_{i t}\right)\right\}$ uma amostra de observações gerada pelo modelo $y_{i t}=g\left(x_{i t}\right)+\varepsilon_{i t}$. Uma RNA permite construir uma aproximação da função desconhecida $g($.$) , da$ forma:

$$
f\left(x_{i t}, \theta\right)=w_{00}+\sum_{j=1}^{h} w_{0 j} \Psi\left(\widetilde{x}_{i t} w_{1 j}\right)
$$

onde:

$$
\begin{aligned}
& w \equiv\left(w_{00} w_{01}, \ldots w_{0 h} w_{11}^{\prime}, \ldots, w_{i h}^{\prime}\right) \\
& \widetilde{x}_{i t} \equiv\left(1, x_{i t}\right), \text { matriz com as variáveis explicativas. } \\
& \Psi(.)=\text { função de ativação, geralmente a função logística. }
\end{aligned}
$$

A RNA apresentada nessa equação é extremamente flexível, podendo representar uma grande variedade de modelos. ${ }^{17}$ Se o número de neurônios aumenta com o tamanho da amostra, podemos interpretá-la como um modelo não paramétrico. Se o número de neurônios é fixo, tem-se um modelo 
semiparamétrico. De acordo com Sarle (1994), as RNAs são especialmente atrativas porque podem variar a sua complexidade de um modelo semiparamétrico simples a um não paramétrico altamente flexível.

O processo de aprendizado da rede consiste exatamente em encontrar os valores para $w$ que resolvam o seguinte problema de otimização não linear:

$$
\min n^{-1} \sum_{t=1}^{n} \pi\left(y_{i t}, f\left(x_{i t}, w\right)\right)
$$

onde $\pi$ (.) é uma função apropriadamente escolhida.

Como exemplo, na equação a seguir, temos um típico problema de mínimos quadrados não lineares:

$$
\min n^{-1} \sum_{t=1}^{n}\left(y_{i t}^{-} f\left(x_{i t}, w\right)\right)^{2}
$$

Em uma regressão não linear paramétrica, a expressão $f\left(x_{i t}, w\right)$ representa uma família de curvas em que a forma funcional é definida antecipadamente; o problema é obter o estimador $\hat{w}$ ótimo, que minimiza o erro quadrático médio. Mais especificamente, o problema de estimação consiste em obter um membro específico dessa família de curvas que dê o melhor ajuste aos dados. White (1992) mostra que o estimador de mínimos quadrados não lineares tende assintoticamente para os pesos ótimos "aprendidos" pela RNA. Como salientado em Fernandes, Portugal e Navaux (1996), a grande novidade introduzida pelas RNAs consiste em focalizar a atenção na forma funcional. Ainda segundo os autores, é nesse sentido que os procedimentos de aprendizagem utilizados para obter os pesos consistem em um processo de estimação usual em estatística. A maioria dos métodos utilizados para encontrar os "pesos" ótimos da rede consiste de alguma variação do algoritmo do gradiente descendente, em que os pesos são ajustados na direção contrária ao gradiente, ou seja, na direção em que a função decresce mais rapidamente. ${ }^{18}$

Do exposto, fica claro que a principal vantagem do uso dos modelos de RNAs é a não necessidade de se especificar uma forma funcional para a relação entre as variáveis e a sua grande habilidade em modelar relações não lineares, ou seja, a propriedade de aproximação universal. Contudo, tal propriedade é compartilhada por muitas técnicas de estimação não paramétri- 
ca. De acordo com Campbell, Lo e Mackinlay (1997, p. 515), o principal atrativo da RNA é que ela faz isso através da composição de funções relativamente simples. Ainda, como salientado por Franses e Van Dijk (2000), as RNAs possuem a propriedade de adaptação a informações e eventos anômalos, tais como outliers e mudanças de nível (quebra estrutural).

\section{APLICAÇÃO DE RNAS A DADOS EM PAINEL}

A aplicação de RNAs é mais frequente em problemas que envolvam séries temporais, sendo a análise com dados em painel ainda limitada, já que estes são geralmente analisados por meio de técnicas de estimação apropriadas e específicas (Longhi et al., 2005).

Alguns poucos trabalhos aplicaram RNAs no contexto de dados em painel. Longhi et al. (2005), por exemplo, a utilizam em um painel não balanceado para a previsão de padrões de emprego regional na Alemanha e concluem que essa técnica parece oferecer previsões mais acuradas que as tradicionais. Outras aplicações incluem a estimação de fluxos de investimento direto externo (Plikinas e Akbar, 2006), a política de endividamento de firmas (Pao e Chih, 2006) e a previsão de crises financeiras (Peltonen, 2006). A maioria desses estudos usa o método da retropropagação dos erros para estimar um modelo do tipo pooled cross-section.

No caso de dados em painel, torna-se interessante modelar efeitos não observados relacionados às unidades cross-section ou então efeitos de tempo específicos. Isso poderia, por exemplo, ser realizado por meio da inclusão de dummies, o que, porém, aumentaria de maneira expressiva o número de inputs. Existem, na literatura, outras maneiras de tratar o problema da heterogeneidade não observada (efeitos fixos e efeitos aleatórios, por exemplo). No presente trabalho, segue-se a estratégia de modelagem adotada em Longhi et al. (2005). Os efeitos específicos das unidades de corte serão capturados por meio de uma variável discreta, definida entre os valores de 0 e 1 , assumindo um valor diferente para cada indivíduo, calculada da seguinte forma:

Efeitos individuais $=\frac{i}{N}$ 
onde:

$i$ varia de 1 a $N$

$N=$ tamanho da amostra no corte transversal

De maneira similar, os efeitos específicos de tempo serão capturados a partir da seguinte variável:

Efeitos específicos de tempo $=\frac{t}{T}$

onde:

$t$ varia de 1 a $T$

$T=$ tamanho da amostra no corte temporal

Dessa forma, a equação a ser estimada ${ }^{19}$ consiste basicamente em um modelo neural para dados em painel com efeitos fixos "não tradicional", conforme sugerido em Longhi et al. (2005).

\section{INFERÊNCIA ESTATÍSTICA VÁLIDA EM RNAS}

Racine e White (2001) propuseram um método para verificar a significância das variáveis de entrada (inputs) da rede através de inferência estatística formal. Foram sugeridas duas formas de se testar a significância das entradas da rede: uma baseada em derivadas parciais e outra em comparação de redes. Cabe salientar, porém, que essa metodologia é adequada para dados i.i.d. (com algumas exceções, como veremos). La Rocca e Perna (2005) propuseram uma modificação que torna esse método aplicável também para dados dependentes, como será visto adiante. A sugestão proposta no presente trabalho é a modificação do procedimento de bootstrap no caso de dados em painel sem dependência espacial, conforme apresentada em Kapetanios (2004).

\subsubsection{Procedimento de Racine-White para dados i.i.d.:}

teste baseado em derivadas parciais

Dado o seguinte modelo MLP com uma camada oculta: ${ }^{20}$

$$
f(x, w)=w_{00}+\sum_{j=1}^{h} w_{0 j} \psi\left(\tilde{x} w_{1 j}\right)
$$


onde:

$\psi=$ função de ativação da rede (que, em nosso caso, é a função

logística)

$\tilde{x}=\left(1, x^{T}\right)^{T}$

Testar a hipótese de que certas entradas da rede não possuem efeito qualquer no produto dessa rede equivale a testar a hipótese de que as derivadas parciais em relação a essas entradas são iguais a 0 , ou seja:

$$
\frac{\partial f\left(x, w^{*}\right)}{\partial x_{i}}=0 \quad i \in I_{0}
$$

onde:

$w^{*}$ são os pesos “ótimos” encontrados para a rede durante

o treinamento;

$I_{0}$ é o conjunto de entradas cuja relevância deseja-se testar.

Quando se trabalha com funções não lineares, a derivada parcial não é constante, mas dependente dos valores assumidos pelas variáveis explicativas. Assim, uma medida de relevância de um conjunto de entradas deve ser baseada em alguma função das derivadas parciais, como a dada a seguir, por exemplo:

$$
m=\sum_{i \in I_{0}} \int f_{i}\left(x, w^{*}\right)^{2} d \mu(x)
$$

onde:

$$
\begin{aligned}
& f_{i}\left(x, w^{*}\right)=\frac{\partial f\left(x, w^{*}\right)}{\partial x_{i}} \\
& \mu(x)=\text { distribuição de probabilidade de } X_{t}
\end{aligned}
$$

A condição (I) será verdadeira se e somente se $m^{\star}=0$. Note, porém, que $w^{*}$ e $\mu(x)$ são desconhecidos, mas o peso $\hat{w}_{n}$ encontrado durante o treinamento da rede e a distribuição empírica de $X$ são consistentemente estimados por $w^{\star}$ e $\hat{\mu}_{n}$, respectivamente. Uma estatística factível é então:

$$
\hat{m}_{n}=\frac{1}{n} \sum_{t=1}^{n} \sum_{i \in I_{0}} f_{i}\left(X_{t}, \hat{w}_{n}\right)^{2}=\int \sum_{i \in I_{0}} f_{i}\left(X, \hat{w}_{n}\right)^{2} d \hat{\mu}_{n}(x)
$$


Racine e White (2001, p. 660) derivaram a distribuição assintótica dessa estatística, com a suposição principal de que $X_{t}$ é uma sequência de vetores aleatórios, mostrando que:

$$
n \hat{m}_{n} \rightarrow N_{2}\left(0, C^{\star} ; M^{\star}\right)
$$

Essa distribuição é a composição de $X^{2}$ s independentes ${ }^{21}$ onde $C^{\star}$ é a matriz de covariância (semidefinida positiva) e $M^{\star}=\mathrm{E}\left(\nabla^{2} m\left(X_{t}, w^{\star}\right)\right) / 2$. Tal distribuição pode ser aproximada pela técnica de bootstrap. A estatística bootstrap é dada por:

$$
\bar{\beta}_{n}^{*} \equiv \sum_{t=1}^{n} m\left(X_{t}, \hat{w}_{n}^{*}\right)-\sum_{t=1}^{n} m\left(X_{t}, \hat{w}_{n}\right)-\sum_{t=1}^{n} \nabla^{T} m\left(X_{t}, \hat{w}_{n}\right)\left(\hat{w}_{n}^{*}-\hat{w}_{n}\right)
$$

onde:

$\hat{w}_{n} \cdot=$ pesos "ótimos" da rede treinada com a reamostra de $X_{t}$ e $Y_{t}$.

$$
m(x, w)=\sum_{i \in I_{0}} f_{i}(x, w)^{2}
$$

Pelo Teorema 2.3 (Racine e White, 2001, p. 662):

$$
\bar{\beta}_{n}^{*} \stackrel{d}{\longrightarrow} N_{2}\left(0, C^{\star} ; M^{\star}\right)
$$

O procedimento para o teste de significância das entradas da rede é sumarizado a seguir.

(i) Será calculada uma reamostra com reposição de $\left\{X_{t}, Y_{t}\right\}$, que chamaremos de $\left\{X_{t}^{*}, Y_{t}^{*}\right\}$. Estimaremos, então, um novo modelo com $\left\{X_{t}^{*}, Y_{t}^{*}\right\}$. O algoritmo de treinamento será iniciado a partir dos valores iniciais $\hat{w}_{n}$ encontrados para a rede treinada originalmente. Com esses pesos reamostrados e os pesos iniciais, poderemos então computar a estatística bootstrap:

$\bar{\beta}_{n}^{*} \equiv \sum_{t=1}^{n} m\left(X_{t}, \hat{w}_{n}^{*}\right)-\sum_{t=1}^{n} m\left(X_{t}, \hat{w}_{n}\right)-\sum_{t=1}^{n} \nabla^{T} m\left(X_{t}, \hat{w}_{n}\right)\left(\hat{w}_{n}^{*}-\hat{w}_{n}\right)$

(ii) O procedimento descrito em (i) será repetido 500 vezes. Portanto, obteremos 500 valores para a estatística bootstrap. Dessa forma, poderemos computar a região de aceitação da hipótese nula $\left(\mathrm{c}_{\alpha}\right)$. 
(iii) A estatística $n \hat{m}_{n}$ será calculada. Se for maior que $c_{\alpha}$, a hipótese nula deverá ser rejeitada.

\subsubsection{Inferência para dados dependentes: \\ o uso do bootstrap em bloco}

A aplicação do bootstrap padrão a dados dependentes não fornece resultados consistentes, já que desconsidera a estrutura de dependência dos dados. Uma possível alternativa é a utilização do método de subamostragem, no qual blocos de observações consecutivas são obtidos da série original, tratando cada subsérie como uma série temporal válida. A estatística de teste é avaliada, então, em todas as subséries.

Em particular, pelo Teroma 1 e o Corolário 2 de La Rocca e Perna (2005, p. 420-421), o procedimento de Racine e White pode ser extendido a dados dependentes com o requerimento adicional para que o processo seja estacionário e strong mixing. ${ }^{22} \mathrm{O}$ procedimento de bootstrap, no entanto, deve ser modificado para levar em consideração a dependência dos dados. A técnica sugerida é a do bootstrap em bloco citada anteriormente. Dessa forma, o procedimento de reamostragem deve ser alterado conforme descrito a seguir:

(i) Fixa-se uma subsérie (bloco) em $b$, fazendo $Y_{b, t}=\left(Y_{t}, \ldots, Y_{t+b-1}\right) \mathrm{e}$ $X_{b, t}=\left(X_{t}, \ldots, X_{t+b-1}\right)$ subséries de $b$ observações consecutivas da amostra original.

(ii) Seja $\hat{W}_{T, b, t}$ a estimativa do vetor de parâmetros calculados para essas subséries e $\hat{m}_{T, b, t}$ a estatística de teste calculada para cada uma dessas subamostras. Repetindo esse processo para cada subsérie, nós podemos aproximar a distribuição amostral da estatística de teste através de:

$$
\hat{G}_{T, b}(x)=\frac{1}{T-b+1} \sum_{i=1}^{T-b+1} I\left(b \cdot m_{T, b, t} \leq x\right)
$$

em que $I$ (.) é a função indicador.

(iii) O valor crítico para o teste é obtido como o quantil de ordem $(1-\alpha)$ de $\hat{G}_{T, b}($.$) .$

O principal problema em aplicar esse tipo de procedimento está na escolha da duração do bloco, ou seja, na variável $b$. Contudo, pelo Teorema 2.7.1, apresentado em Politis et al. (1999), resultados assintóticos são válidos para um amplo intervalo de escolha de $b$. 


\subsubsection{Inferência em um painel de dados com dependência temporal e ausência de dependência espacial}

A literatura a respeito do bootstrap para dados em painel tem focado principalmente na dimensão tempo. Kapetanios (2004) considera a questão do procedimento de bootstrap no contexto de dados em painel e sugere uma possibilidade que não tem sido amplamente explorada pela literatura no assunto. A sua sugestão é reamostrar com substituição apenas as unidades cross-section. Nos casos em que os dados apresentam dependência temporal, mas não espacial, é possível com esse procedimento aplicar abordagens do bootstrap para dados i.i.d. em vez da aplicação do bootstrap em bloco, por exemplo. O autor mostra, através de um estudo de Monte Carlo, que o bootstrap baseado apenas nas unidades cross-section tem performance superior quando comparado ao bootstrap em bloco.

No contexto de dados em painel, as seguintes abordagens de reamostragem são possíveis: reamostragem temporal, cross-sectional, temporal e crosssectional simultaneamente, as quais são detalhadas a seguir. Considerando uma matriz $\mathrm{Y}$, de dimensão $\mathrm{T} \times \mathrm{N}$, temos as seguintes definições:

(a) Reamostragem cross-sectional: é definida como a operação de construir uma matriz $\mathrm{T} \times \mathrm{N}^{*}$, denominada $\mathrm{Y}^{*}$, em que as colunas (ou blocos de colunas, para dados dependentes) de $\mathrm{Y}^{*}$ são uma reamostra aleatória com substituição das colunas de $\mathrm{Y}$, e $\mathrm{N}^{\star}$ não é necessariamente igual a $\mathrm{N}$.

(b) Reamostragem temporal: consiste em construir uma matriz $\mathrm{Y}^{\star}$, com dimensão $\mathrm{T}^{*} \times \mathrm{N}$, em que as linhas de $\mathrm{Y}^{*}$ são uma reamostra aleatória com substituição das linhas (ou blocos de linhas) de $\mathrm{Y}$, e T não é necessariamente igual a $\mathrm{T}$.

(c) Reamostragem temporal e cross-sectional: é definida como a operação de construir uma matriz $\mathrm{T}^{*} \times \mathrm{N}^{*}$, em que as colunas e linhas de $\mathrm{Y}^{\star}$ são uma reamostra aleatória com substituição das colunas de $\mathrm{Y}$, e $\mathrm{N}^{*}$, $\mathrm{T}^{*}$ não são necessariamente iguais à $\mathrm{N}, \mathrm{T}$.

O autor realiza um estudo de Monte Carlo para os vários arranjos de reamostragem descritos. Seus resultados permitem afirmar que, quando a dimensões $\mathrm{T}$ e $\mathrm{N}$ aumentam juntas, a performance relativa da reamostragem cross-sectional utilizando o bootstrap para dados i.i.d. é melhor que a reamostragem temporal utilizando o bootstrap em bloco. Os resultados 
também sugerem que essa afirmação é verdadeira para uma grande variedade de modelos de dados em painel.

Neste trabalho, adota-se o procedimento de reamostragem sugerido por Kapetanios (2004). É razoável supor, nesse caso, que as expectativas inflacionárias apresentem dependência temporal, porém não apresentem correlação espacial, evitando, assim, o uso do bootstrap em bloco, que, como salientam Lahiri (2003) e Andrews (2002), tem fornecido aproximações menos acuradas que o bootstrap "padrão".

\section{ANÁLISE EMPÍRICA}

\subsection{Descrição dos dados}

\subsubsection{Expectativas de inflação}

Os dados para as previsões de inflação são referentes às expectativas mensais para o IPCA acumulado 12 meses à frente, no período de fevereiro/2002 a junho/2006. Para cada mês, temos a informação da expectativa de cada instituição pesquisada pelo Bacen, referente ao período posterior à data de referência ${ }^{23}$ (cinco dias). Os dados foram gentilmente cedidos pelo Gerin. ${ }^{24}$ Foram excluídas da amostra as instituições que contassem com menos de 10 observações durante o período inteiro. Com esse procedimento, a amostra passou a 80 instituições.

O uso de dados de survey como medida de expectativas de inflação é algumas vezes questionado. De acordo com Garcia (1994, p. 48, 67), a análise realizada com dados de inflação esperada obtidos através do preço de ativos financeiros é superior às que se utilizam de surveys de expectativas de inflação. Isso porque, neste último caso, os agentes podem não ter incentivos para revelar suas verdadeiras expectativas. Além disso, Lima e Céspedes (2003) realizam um estudo de habilidade preditiva das expectativas e concluem que estas "não espelham as verdadeiras expectativas do mercado e que, portanto, não deveriam ter qualquer influência na formulação da política monetária do país" (Lima e Céspedes, 2003, p. 83). Carvalho (2004) não compartilha tal argumento, mostrando que o Bacen possui mecanismos de incentivos para que as instituições revelem suas expectativas verdadeiras. Além disso, como salientado em Carvalho e Bugarin (2005, p. 2, nota de rodapé n. 3), o procedimento para extrair as expectativas de instrumentos 
financeiros no caso brasileiro é seriamente comprometido por questões relacionadas à liquidez e ao prêmio de risco (que não é constante no tempo e muito menos negligenciável).

\subsubsection{0 comportamento das expectativas de inflação entre fev./2002 e jun./2006}

O regime de metas de inflação foi adotado no país em junho de 1999, após a implementação da flutuação cambial, em janeiro do mesmo ano, em meio a uma crise relacionada à remoção da âncora cambial, o que exigiu que o Banco Central perseguisse a credibilidade de suas ações com maior vigor.

Gráfico 1: Expectativas de inflação (IPCA) para os próximos 12 meses
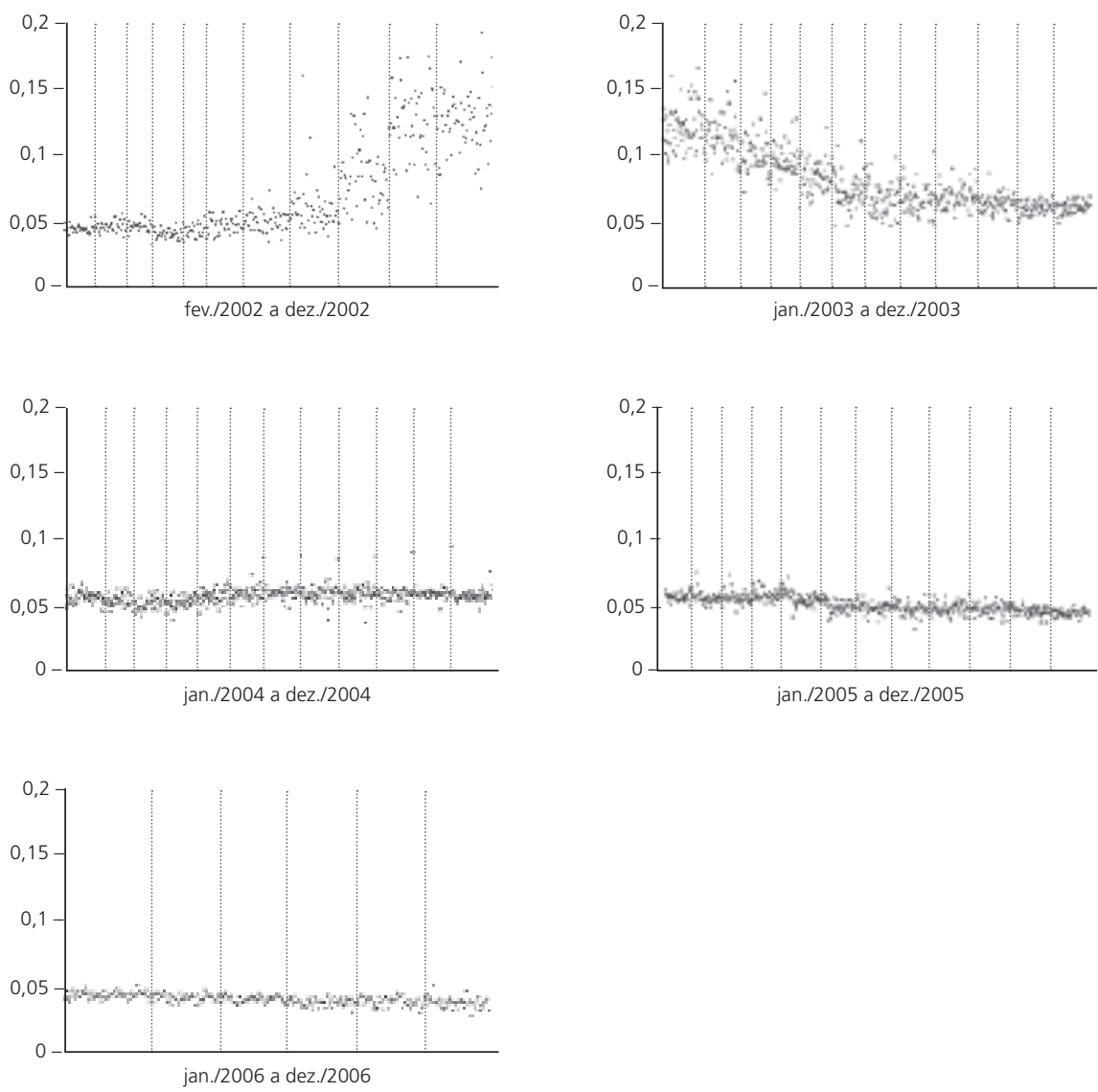

Fonte: Dados do Banco Central do Brasil. 
O instrumento operacional utilizado para alcançar as metas de inflação é a taxa de juros de curto prazo (Selic). Assim, quando a política monetária perde credibilidade, o Banco Central deve aumentar a taxa de juros a fim de controlar a inflação.

O gráfico 2 mostra a evolução das expectativas inflacionárias entre fevereiro/2002 e junho/2006. Como pode ser observado, a partir de agosto/2002, a magnitude das expectativas de inflação, bem como a sua dispersão, inicia um processo de aumento considerável. Essa situação começa a se reverter em meados de 2003.

Esse comportamento pode ser explicado basicamente por dois fatores: a elevada aversão ao risco no cenário internacional ${ }^{25} \mathrm{e}$, principalmente, a crise de confiança que ocorreu no país em 2002. ${ }^{26}$ Nesse período, tivemos um ambiente de credibilidade limitada, já que o excesso de conservadorismo da política monetária foi foco constante de críticas durante a campanha eleitoral (Bevilaqua, Mesquita e Minella, 2007). O risco-Brasil aumentou de 750 pontos em abril de 2002 para 2.400 pontos no final de setembro. A demanda por títulos domésticos diminuiu consideravelmente. A inflação anual, medida pelo IPCA, alcançou 12,53\% em 2002 (em 2001, havia sido de 7,67\%), ficando acima do intervalo de tolerância para a meta $(3,5 \%$ com intervalo de $\pm 2 \%$ ). Houve uma súbita interrupção nos influxos de capital que levou a uma depreciação forte do câmbio. De fato, a depreciação acentuada da taxa de câmbio fez com que as expectativas de inflação aumentassem.

O gráfico 3 apresenta a evolução do erro de previsão da inflação para os próximos 12 meses. Entre fevereiro e agosto de 2002, os agentes subestimaram a inflação. A partir de agosto/2002, os agentes passam a ter expectativas de inflação mais altas, tendendo a superestimar a inflação. Nesse contexto, o Banco Central, que vinha até então reduzindo a taxa de juros, decidiu por um aumento nesse instrumento, passando de $18 \%$ a.a. (julho/2002) para $21 \%$ a.a. (outubro/2002). A taxa Selic sofreu, então, aumentos sucessivos, atingindo o pico de $26,5 \%$ em fevereiro/2003.

Com a instalação do novo governo em 2003 e a efetiva continuidade da política macroeconômica do governo anterior, a incerteza diminuiu e as expectativas começaram a se reverter, ou seja, tanto sua magnitude quanto dispersão diminuíram. ${ }^{27}$

A tendência dos agentes em superestimar a inflação acumulada se mantém até meados de 2003, quando o erro de previsão passa a ser predominan- 


\section{Gráfico 2: Erro de previsão, IPCA para os próximos 12 meses}

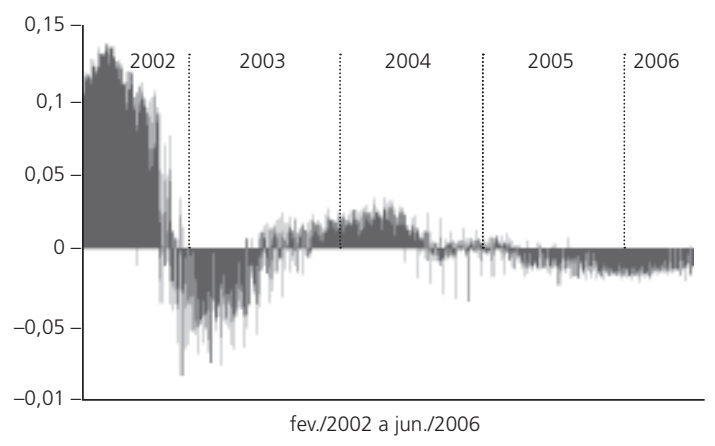

Fonte: Dados do Banco Central do Brasil e IBGE.

Gráfico 3: Desvio padrão dos erros de previsão e EQM, fev./2002 a jun./2006
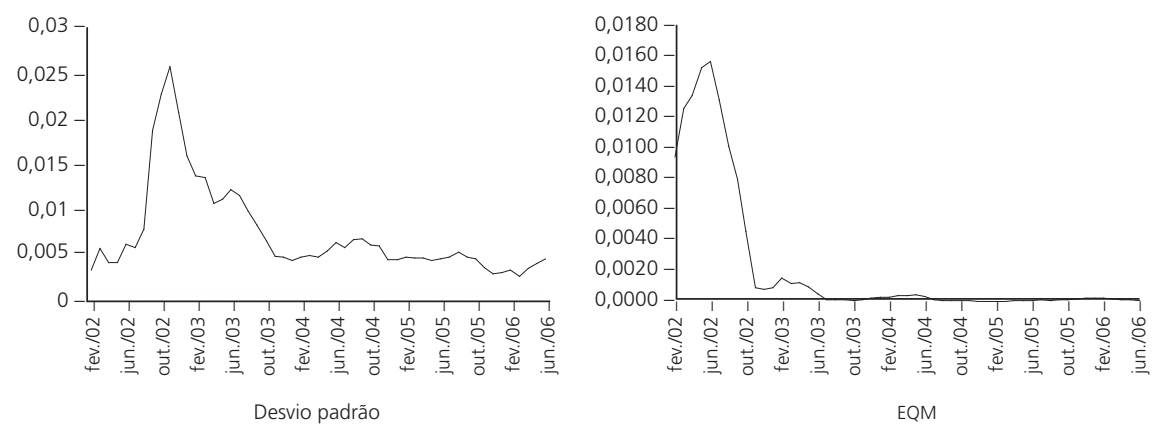

temente positivo, ou seja, os agentes novamente passam a subestimar a inflação acumulada em 12 meses, tendência que se mantém até meados de 2004. A partir de então, os agentes passam novamente a superestimar a inflação. Em meados de 2004, houve um aumento da inflação: o IPCA acumulado em 12 meses passou de 5,15\% em maio 2004 para 7,18\% em agosto do mesmo ano, o que pode explicar essa revisão para cima das expectativas. De acordo com Garcia (2006), os preços administrados foram os principais responsáveis por esse crescimento do índice de preços, já que os choques de oferta que afetaram a economia em 2002 e 2003 foram transmitidos a estes pela regra de indexação. Os preços livres também se elevaram, o que indica que o aumento dos preços de produtos administrados foi repassado aos preços livres. Dessa forma, em setembro de 2004, a taxa Selic foi novamente elevada para conter o aumento da inflação, atingindo o ápice em maio de $2005(19,75 \%)$ e voltando a cair apenas em setembro de 2005 (19,5\%). 
É claro, a partir dos gráficos 2 e 3, o período de consolidação da desinflação a partir de 2005. O erro de previsão vem diminuindo consideravelmente, bem como a incerteza sobre a inflação futura (medida pelo desvio padrão das expectativas). Esse comportamento parece refletir um ambiente mais estável e previsível, com um maior entendimento por parte do mercado da dinâmica da inflação.

\subsubsection{Variáveis explicativas}

A seguir apresenta-se o conjunto de variáveis que podem, a princípio, ser explicativas do processo de formação de expectativas no Brasil. As variáveis foram escolhidas com base teórica, em estudos anteriores e de acordo com as observações realizadas na seção anterior.

Defasagens de primeira e segunda ordem das expectativas de inflação.

Fonte: Banco Central do Brasil

Surpresa de curto prazo do IPCA-15:28 IPCA - 15 $t_{t}-E_{t-1}$ (IPCA - 15).

Fonte: Banco Central do Brasil e IBGE

Surpresa de curto prazo da inflação: IPCA $A_{t}-E_{t-1}\left(I P C A_{t}\right)$.

Fonte: Banco Central do Brasil e IBGE

IPCA acumulado em 12 meses com um período de defasagem (IPCA $\left.A_{t-1}^{12 M}\right)$.

Fonte: Banco Central do Brasil e IBGE

Variação do risco-Brasil (Embi Brasil) com um período de defasagem.

Fonte: Macrodados

Hiato do produto com três períodos de defasagem: ${ }^{29}$ desvio entre o produto real e o potencial, calculado

através do filtro de Hodrick-Prescott e com a utilização da série da produção industrial dessasonalizada.

Fonte: Dados da produção industrial - IBGE

Taxa de juros Selic efetiva (\% a.a.), com um período de defasagem.

Fonte: Banco Central do Brasil

Meta de inflação: a meta para a inflação acumulada em 12 meses foi obtida por interpolação linear ${ }^{30}$ das metas anuais:

$$
\pi_{12 m, t+12}^{T} \frac{12-i}{12} \pi_{t}^{T}+\frac{i}{12} \pi_{t+1}^{T}
$$

Fonte: Banco Central do Brasil

"Efeito fixo": variável discreta no intervalo $(0 ; 1)$, que assume um valor diferente para cada instituição.

Dado que temos 80 instituições na amostra, essa variável será dada por:

$\frac{1}{80} \times j$; onde j varia de 1 a 80 e refere-se ao número da instituição.

"Efeito de tempo específico": construída da mesma forma que a variável de efeito fixo:

$\frac{1}{53} \times t$; onde $t$ varia de 0 a 53 e refere-se ao ponto no tempo. 
Variação cambial com um período de defasagem.

Fonte: Banco Central do Brasil

Volatilidade cambial: desvio padrão do câmbio no mês anterior; desvio padrão do câmbio acumulado em três meses; desvio padrão do câmbio acumulado em seis meses.

Resultado primário do governo central (\% PIB).

Fonte: STN - Secretaria do Tesouro Nacional

Dívida total (\% PIB).

Fonte: Banco Central do Brasil

Variação dos preços das commodities com um período de defasagem.

Fonte: Ipea

Desvio padrão médio das expectativas com um período de defasagem.

Fonte: Banco Central do Brasil

Média das previsões médias das instituições Top 5 de longo prazo com um período de defasagem.

Fonte: Banco Central do Brasil

Dummy: foram utilizadas algumas variáveis dummies para o período de crise de confiança, com diversas datas de início e fim entre março de 2002 e fevereiro de 2003 e março de 2003 a agosto de 2003 (pós-crise).

\subsection{Arquitetura da rede}

A definição da arquitetura da rede é uma tarefa bastante complicada, não existindo ainda uma metodologia estabelecida para isso. Como salientam Zhang et al. (1998, p. 42), a definição desses parâmetros é fortemente dependente do problema para o qual se estão utilizando as RNAs. O processo de determinação da arquitetura de uma RNA é chamado por muitos de "magia negra", dada a sua pouca compreensão. Alguns autores, como Anders e Korn (1999); Ripley (1993); Pizarro, Guerrero e Galindo (2000); Medeiros, Teräsvirta e Rech (2006), entre outros, propõem procedimentos estatísticos para essa tarefa. La Rocca e Perna (2005) propuseram um procedimento bastante simples, no qual a escolha das variáveis explicativas é feita através de uma medida de relevância e posterior teste de significância dessas variáveis. A seguir, detalha-se como a arquitetura da rede utilizada no presente trabalho foi escolhida.

Seleção de variáveis de entrada (inputs)

A seleção será feita basicamente de forma empírica. Utiliza-se como guia o procedimento sugerido por La Rocca e Perna (2005), ou seja, um teste estatístico formal para remover aquelas entradas que forem irrelevantes, com algumas adaptações ao problema específico que se tem aqui. A rede geral, com todas as variáveis, será treinada e, com isso, poderemos computar a 
medida de relevância de cada entrada. ${ }^{31}$ As entradas que possuírem tal medida próxima de 0 serão tidas como candidatas à exclusão do modelo. Para tanto, a significância estatística de cada uma será testada. Se não for significante, será treinada uma nova rede sem essa variável. As redes serão comparadas através do CIS.

Número de camadas ocultas (hidden layers)

Existem trabalhos teóricos que mostram que uma camada oculta é suficiente para aproximar qualquer função não linear complexa (veja, por exemplo, Hornik et al., 1989). A maioria dos trabalhos que utilizam RNAs para previsão de séries temporais faz uso de apenas uma camada oculta. ${ }^{32}$ De acordo com Zhang et al. (1998, p. 44), uma camada oculta parece ser adequada para a maioria dos problemas de previsão. Sendo assim, utilizam-se redes com apenas uma camada intermediária.

Número de neurônios na camada oculta (hidden nodes)

Geralmente, o número de neurônios na camada oculta é definido de forma empírica. ${ }^{33}$ Utilizando neurônios demais, a rede poderá memorizar excessivamente os dados de treinamento, levando a overfitting (excesso de ajustamento) e, consequentemente, a uma baixa capacidade de generalização. Utilizando poucos neurônios, o treinamento poderá ser extremamente lento.

Seguindo Racine e White (2001), a complexidade da rede será determinada com o auxílio do Critério de Informação de Schwarz (CIS). Para tanto, utilizaremos de 1 a $2 i+1$ unidades ocultas ( $i=$ número de inputs) e 10 reinícios aleatórios de pesos iniciais para cada conjunto de unidades de entrada. ${ }^{34}$ A configuração que produzir o menor valor para o CIS, para cada rede, será, então, escolhida como a melhor, dado o número de variáveis de entrada.

Função de ativação

Será utilizada a função sigmoide (logística) ${ }^{35}$ para os neurônios da camada intermediária e a função linear "pura" (ou identidade) para o neurônio de saída.

\subsection{Treinamento e avaliação das redes}

Para o treinamento das redes, utiliza-se o algoritmo do gradiente conjugado. Para evitar a ocorrência de um mínimo local, o algoritmo é imediata- 
Tabela 2: Testes para linearidade na média ${ }^{38}$

\begin{tabular}{lcc}
\hline Teste & Estatística & Valor-p \\
\hline Teräsvirta & 1356,156 & $<2,2$ e -16 \\
\hline White & 7,7629 & 0,02062 \\
\hline
\end{tabular}

mente reiniciado a partir do ponto em que o treinamento foi encerrado. Além disso, reinícios aleatórios dos pesos iniciais são também utilizados. As redes foram treinadas com o auxílio do programa Matlab.

Uma questão bastante relevante quando se inicia o treinamento é decidir se as variáveis serão ou não "normalizadas". ${ }^{36}$ Se sim, resta ainda decidir qual tipo de "normalização" será utilizada. Não há ainda um consenso sobre a necessidade ou não de se realizar a normalização das variáveis. Shanker et al. (1996), por exemplo, avaliam os benefícios no treinamento da rede de se realizar a normalização linear e estatística nas variáveis. ${ }^{37}$ Eles concluem que, em geral, há, sim, benefícios em se realizar a normalização, mas estes diminuem quando o tamanho da rede e da amostra aumentam. Palma e Sartoris (2006), por exemplo, encontraram melhores resultados com a normalização estatística, a qual será empregada no presente trabalho.

Outra questão que deve ser ressaltada é em relação à estacionariedade das séries. Como a duração temporal que temos aqui é pequena, a robustez dos testes de estacionariedade ficaria comprometida. Por isso, eles foram omitidos da análise.

Para assegurar que a série em questão trata-se realmente de um processo não linear, testa-se a linearidade do processo gerador da média dos dados através dos testes propostos por Lee, White e Granger (1993) e Teräsvirta, Lin e Granger (1993). Os resultados apresentados na tabela 2 indicam que se pode rejeitar a hipótese nula de linearidade na média a 5\% de significância. Assim, um modelo não linear para as expectativas parece ser realmente o mais adequado.

\subsection{Resultados}

Como a amostra diminui consideravelmente com a inclusão da surpresa de curto prazo do IPCA-15, foram feitas algumas tentativas de treinamento para testar a significância dessa variável. Em nenhuma das tentativas esta se mostrou estatisticamente significante a $10 \%$ (o valor $-p$ girava em torno de 
40\%). A inclusão dessa variável era a razão de usar esse modelo com redução significativa da amostra. Dessa forma, a análise foi realizada com a amostra completa, sem a utilização da surpresa de curto prazo do IPCA -15. Além disso, foi feito um experimento para verificar a correlação entre a variação das expectativas entre cinco dias antes e cinco dias depois da data de referência com a variação do IPCA -15. O coeficiente de correlação encontrado foi de 0,18 , ou seja, bastante baixo.

Várias tentativas de treinamento foram feitas com o modelo mais geral (o que inclui todas as variáveis), seguindo o método exposto na seção anterior. ${ }^{39}$ Cabe ressaltar que, como o efeito do hiato do produto se mostrou insignificante em todas as tentativas de estimação, tentamos substituir essa variável pela taxa de crescimento do produto (também defasada), mas esta se mostrou também insignificante. O modelo final é apresentado na tabela 3a e a performance de previsão, na tabela $3 b$.

Como pode ser observado pelo gráfico 4 , a maior influência sobre as expectativas inflacionárias no período como um todo foi da volatilidade cambial, seguida pela variação no preço das commodities, pela variação cambial e pela meta. A tabela 3a mostra que todas as variáveis, com exceção da surpresa de curto prazo do IPCA, são estatisticamente significantes a 5\%. Como a surpresa de curto prazo se mostrou insignificante, treinamos uma nova rede sem tal variável, mas o CIS diminuiu e, dessa forma, continuamos com o modelo apresentado.

Para avaliar o efeito de cada uma das variáveis apresentadas sobre as expectativas, procede-se à análise de sensibilidade do produto da rede. Para facilitar esse estudo, foi feita a distinção entre três períodos específicos: anterior à crise de 2002 (abr./2002 a ago./2002), período de crise (set./2002 a ago./2003) e posterior à crise (set./2003 a abr./2006). A sensibilidade do produto da rede a variações de $1 \%$ em cada uma das entradas é apresentada no gráfico 5.

É interessante notar o comportamento da influência da meta de inflação sobre as expectativas. Durante o período de crise de confiança, o efeito da meta sobre a inflação esperada é expressivamente menor que nos demais, e mesmo declinante. O contrário ocorre nos outros períodos, atentando para o fato que as expectativas vêm crescentemente sendo influenciadas pela meta no período recente, o que é um indício de que a credibilidade da auto- 
Tabela 3: RNA para a função de reação das expectativas de inflação

(a) Inferência sobre a relevância das variáveis ${ }^{40}$

\begin{tabular}{lccc}
\hline Variáveis & Estatística de teste & Valor crítico (5\%) & Valor-p \\
\hline Lag1 & 11,3942 & 4,9718 & 0,0075 \\
\hline Lag2 & 1,6019 & 0,7283 & 0,0150 \\
\hline Taxa Selic & 0,9722 & 0,5591 & 0,0300 \\
\hline Meta12m & 7,5385 & 3,1788 & 0,0275 \\
\hline Efeito fixo & 1,2669 & 0,5376 & 0,0100 \\
\hline Resultado primário & 6,4898 & 2,7268 & 0,0050 \\
\hline Volatilidade câmbio & 40,4015 & 15,9243 & 0,0100 \\
\hline Câmbio & 11,3130 & 4,0952 & 0,0050 \\
\hline Commodities & 21,2838 & 10,1793 & 0,0150 \\
\hline Surpresa curto prazo IPCA & 0,5974 & 14,3106 & 0,6075 \\
\hline Teste conjunto (todas as variáveis) & 102,8591 & 37,4940 & 0,0075
\end{tabular}

Número de neurônios na camada oculta: 5 .

Quantidade total de pesos: 61.

(b) Performance de Previsão da RNA

\begin{tabular}{lcc}
\hline Estatística & Conjunto de treinamento & Conjunto de validação \\
\hline RMSE & 0,00635 & 0,00341 \\
\hline MAE & 0,00373 & 0,00273 \\
\hline MAPE & 0,05478 & 0,06757 \\
\hline SIGN & 1,00000 & 1,00000 \\
\hline Coeficiente de correlação & 0,96487 & 0,52361 \\
\hline CIS & $-6,24956$ & ---- \\
\hline
\end{tabular}

Nota: $\mathrm{RMSE}$ = raiz quadrada do erro quadrático médio; MAE = erro absoluto médio; MAPE = erro percentual absoluto médio; SIGN = proporção de vezes que o sinal do produto da rede é corretamente previsto; CIS = critério de informação de Schwarz.

\section{Gráfico 4: Medida de relevância}

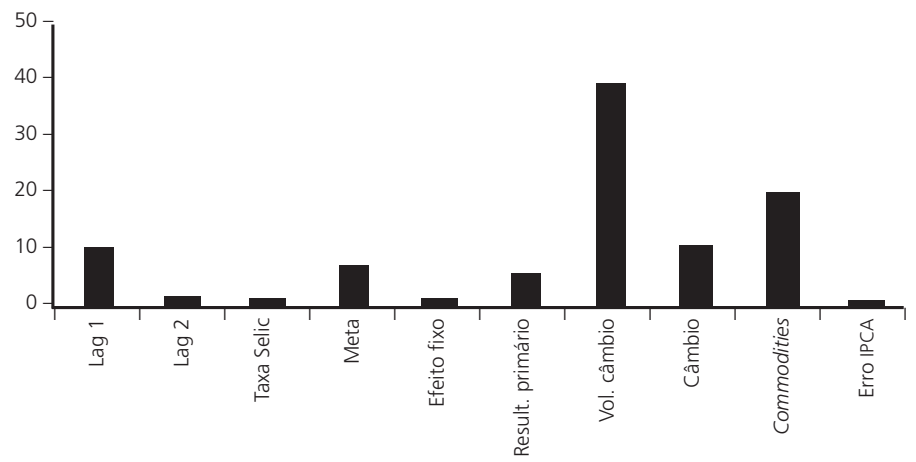


Gráfico 5: Sensibilidade do produto da rede a uma variação de $1 \%$ em cada input

(a) Defasagem de ordem 1
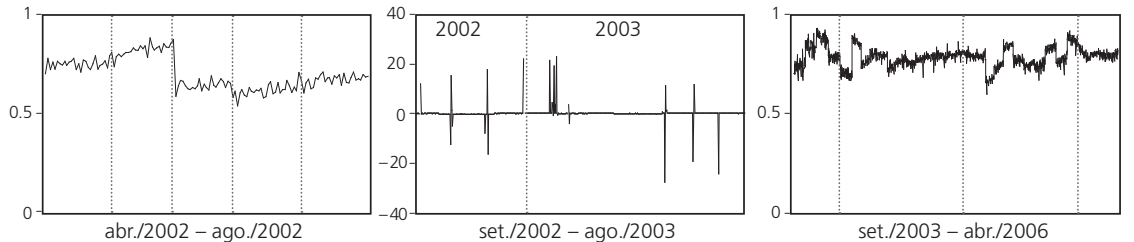

(b) Defasagem de ordem 2
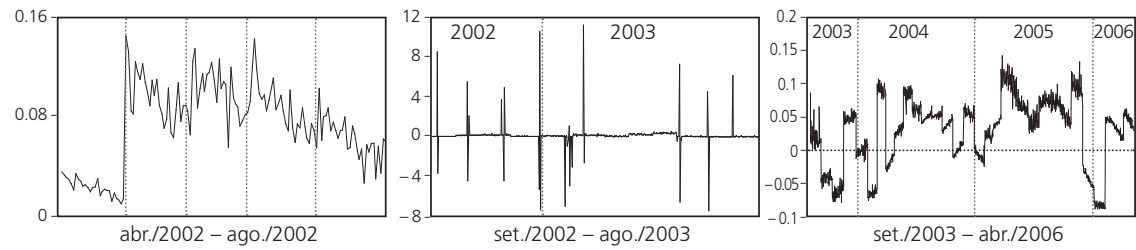

(c) Taxa Selic
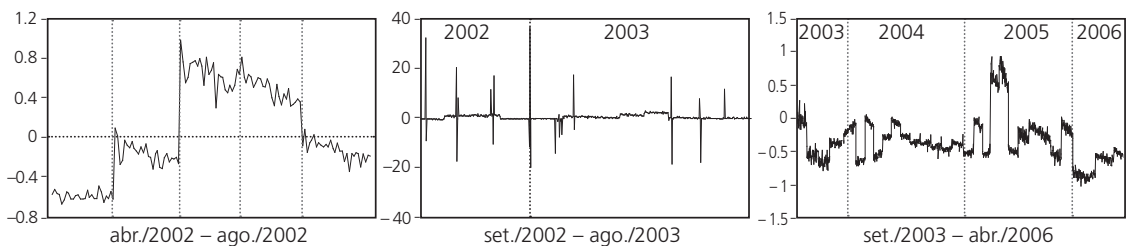

(d) Meta 12 meses
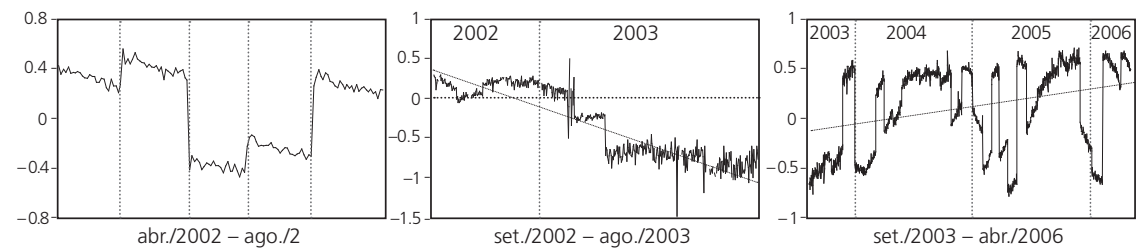

(e) Resultado primário
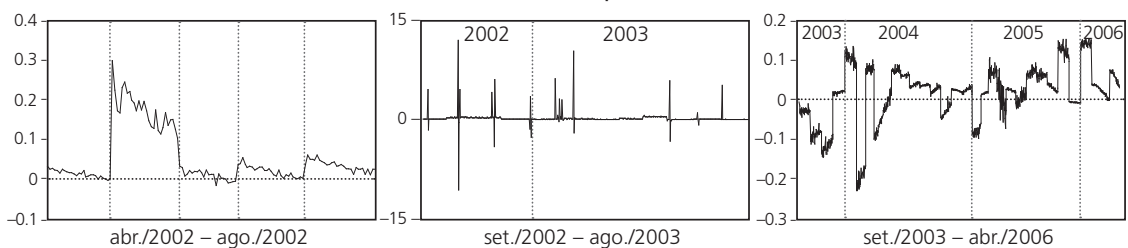
(f) Volatilidade cambial
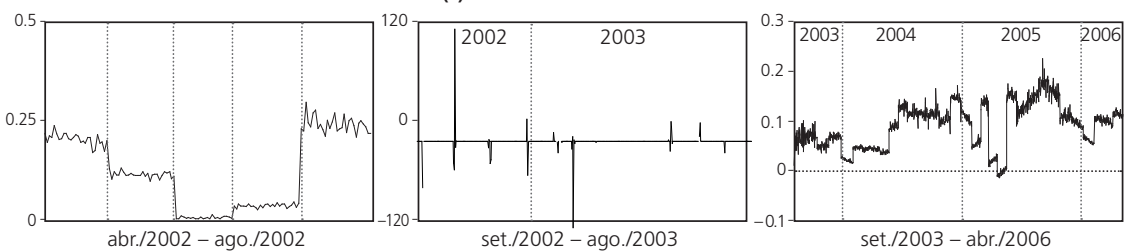

(g) Variação cambial
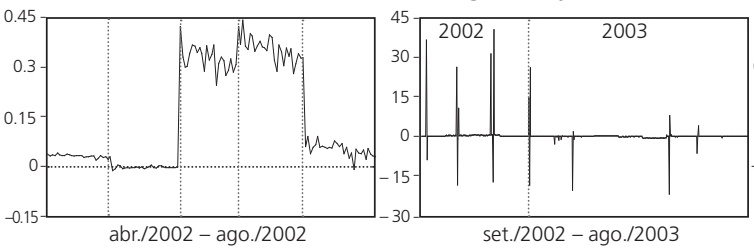

set./2002 - ago./2003

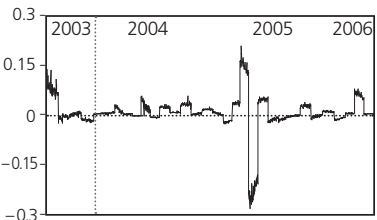

set./2003-abr./2006

(h) Commodities
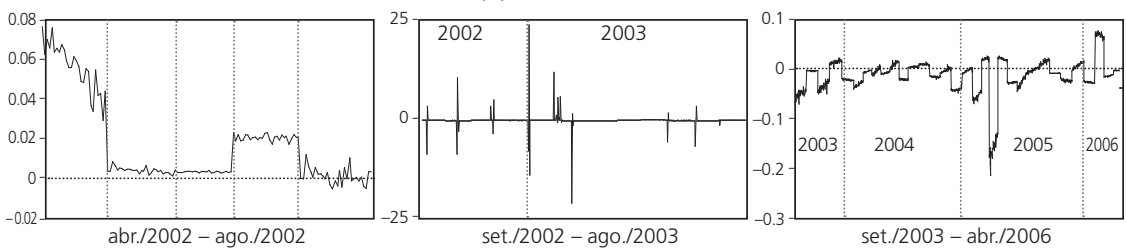

(i) Surpresa curto prazo IPCA
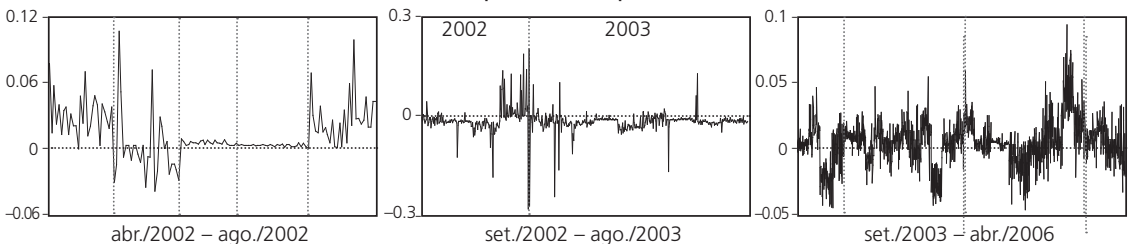

ridade monetária vem aumentando. ${ }^{41}$ Esse resultado é consistente com o obtido, por exemplo, em Bevilaqua et al. (2007). Carvalho e Bugarin (2005) apresentam, também, evidências de que, durante o final de 2002 e início de 2003, as previsões de inflação foram feitas ignorando totalmente a meta de inflação. O coeficiente de variação (médio) aqui obtido é ainda menor que aqueles encontrados pelos trabalhos anteriores, o que sugere que a credibilidade é imperfeita, havendo espaço para melhoria. Para o período de abril 2006, por exemplo, o efeito médio de uma variação de $1 \%$ na meta é de 
0,65\%. Se a credibilidade do Banco Central fosse perfeita, esse coeficiente deveria ser igual a 1 (ou bem próximo de 1).

A taxa Selic tem também um comportamento interessante. No período da crise de confiança, as expectativas de inflação dos agentes reagem predominantemente de maneira positiva a variações da taxa de juros. No período de início da implementação do regime de metas de inflação (pré-crise de confiança), há episódios de reação negativa (abril-maio/2002 e agosto/2002) e episódios de reação positiva (junho-julho/2002), com a reação positiva tendo um efeito maior sobre as expectativas. No período pós-crise, esse efeito é predominantemente negativo e maior em magnitude. Os resultados obtidos por Carvalho e Bugarin (2005) apontavam para um efeito positivo da taxa Selic sobre as expectativas, que foi justificado pelos autores como sendo proveniente de uma possível relação não linear entre essas variáveis. Minella et al. $(2002,2003)$ também encontram um efeito positivo da taxa de juros defasada sobre as expectativas de inflação e explicam que isso pode ser resultado da reação das taxas de juros a pressões inflacionárias: se é prevista uma inflação mais alta pela autoridade monetária e pelo mercado, a taxa de juros é aumentada, mas, apesar disso, os efeitos inflacionários não são completamente eliminados, já que existem defasagens nos mecanismos de transmissão da política monetária e o Banco Central leva em consideração a volatilidade do produto em suas decisões; além disso, os movimentos na taxa de juros refletem também as expectativas de inflação do Banco Central, já que este reage às suas próprias expectativas inflacionárias também.

Nosso argumento para o efeito ambíguo da taxa de juros sobre as expectativas, contudo, é de que esse efeito pode estar associado à influência também ambígua da taxa de juros sobre o câmbio, a qual é derivada do efeito da taxa de juros sobre a dívida. Gonçalves e Guimarães (2006), por exemplo, apresentam evidências empíricas de que o efeito usual que liga aumentos da taxa de juros a apreciação cambial foi superado pelo efeito da dominância fiscal (o qual liga aumentos da taxa de juros a depreciação cambial) no período de 2000 a 2005. A paridade descoberta da taxa de juros implica que um aumento nos juros torna os títulos domésticos mais atrativos, o que aumenta os influxos de capital, aumentando a oferta de dólares no mercado de câmbio e, assim, apreciando a taxa de câmbio (dólar fica mais barato), o 
que leva à diminuição das expectativas de inflação. Porém, o aumento da taxa de juros pode ser interpretado como uma elevação do risco de default, o que levaria a uma depreciação do câmbio e consequente aumento das expectativas. Com isso, um aumento da taxa de juros pode levar a expectativas de inflação mais altas, e não mais baixas. Pelos resultados obtidos aqui, e de acordo com a argumentação anterior, teriam existido períodos (junho/2002 a julho/2002 e maior parte do período de crise) em que o efeito de dominância fiscal cobriu o efeito usual da taxa de juros sobre o câmbio (dado pela condição de paridade-juros descoberta). No entanto, o contrário ocorre no período mais recente, ou seja, a transmissão da taxa de juros sobre as expectativas inflacionárias se dá pelos canais usuais.

O efeito da variação cambial sobre as expectativas é predominantemente positivo (ou seja, a depreciação do câmbio leva a uma elevação da inflação esperada) e também mais baixo no período mais recente (pós-crise de 2002), indicando uma redução no pass-through ${ }^{42}$ na economia, como também evidenciado em Bevilaqua et al. (2007) e Schmidt-Hebbel e Werner (2002). Esse comportamento é consistente com o papel crescente exercido pela meta de inflação. É interessante notar que os resultados obtidos por Minella et al. $(2002,2003)$ indicavam a não significância da variação do câmbio sobre as expectativas de inflação dos agentes. ${ }^{43} \mathrm{~A}$ influência da variação do câmbio sobre as expectativas de inflação apresentada aqui é, em média, também menor que a encontrada em trabalhos anteriores.

A volatilidade cambial exerce um papel significativo e positivo na formação de expectativas. Assim como a variação cambial, a volatilidade do câmbio vem exercendo um papel declinante sobre as expectativas, porém ainda bastante expressivo. Ao que parece, nenhum outro estudo tinha levado em consideração o efeito da volatilidade cambial sobre as expectativas inflacionárias. Um dos principais desafios do regime de metas de inflação em economias emergentes, como o Brasil, é trabalhar com a elevada volatilidade da taxa de câmbio, já que essas economias são mais sensíveis aos efeitos de crises financeiras (Minella et al., 2002, e Pastore et al., 2004). Uma volatilidade maior significa maior incerteza, o que deve impactar as expectativas dos agentes. A volatilidade do câmbio gera frequentes revisões das expectativas inflacionárias, podendo resultar em um não cumprimento da meta. Dado o 
resultado aqui obtido de que as expectativas reagem fortemente à volatilidade cambial, é interessante manter a estabilidade da moeda nacional. Albuquerque e Portugal (2006) encontraram uma relação positiva entre a volatilidade cambial e a volatilidade inflacionária, ou seja, a variabilidade do câmbio aumenta a incerteza; essa maior incerteza afeta as expectativas de inflação dos agentes acerca da inflação futura. Porém, seus resultados indicavam para uma resposta menor da inflação em face da volatilidade cambial em períodos de crise, em que a volatilidade fosse muito alta. Os resultados aqui obtidos sugerem uma influência maior da volatilidade cambial sobre as expectativas de inflação no período de crise cambial.

A variação do preço das commodities é significante e seu efeito apresenta comportamento predominantemente positivo no período de crise e précrise e predominantemente negativo no período pós-crise. Um aumento no preço das commodities pode ser interpretado como um choque adverso de custos, levando a um aumento nas expectativas de inflação. Contudo, uma variação positiva nessa variável afeta os termos de troca (relação entre os preços das exportações e os preços das importações) de maneira positiva em países exportadores de commodities, levando a uma apreciação da taxa futura de câmbio. Assim, uma variação positiva no preço das commodities levaria a uma valorização da taxa cambial, diminuindo as expectativas inflacionárias, o que, de fato, vem ocorrendo no período recente.

O efeito do resultado primário é predominantemente positivo, em quaisquer dos períodos considerados. Poderíamos esperar que esse efeito fosse negativo, ou seja, um aumento no resultado primário reduziria as expectativas de inflação, já que poderia ser entendido como a existência de uma maior coordenação entre as políticas monetária e fiscal (a política fiscal ajuda a política monetária no combate à inflação). Além disso, o aumento do superávit primário pode ser visto também como uma redução no risco de default da dívida, levando à diminuição do prêmio de risco, o que afetaria de maneira inversa as expectativas indiretamente via o efeito da taxa de câmbio. ${ }^{44}$ Porém, há uma certa preocupação ainda em relação à evolução das contas públicas, com evidências de que o resultado primário positivo no Brasil vem sendo conseguido à custa de impostos elevados e corte nos investimentos. No período como um todo, a política monetária esteve sobrecar- 
regada com um quadro fiscal problemático persistente. Como bem salientado por Werneck (2006), houve uma melhora importante na situação fiscal, mas esta foi bem mais favorável pelo lado das contas externas. Ainda de acordo com Werneck (2006), o ajuste fiscal à brasileira é caracterizado pelo aumento do superávit primário consolidado (incluindo estados e municípios) e expansão simultânea de gastos primários. Uma das causas para esse efeito positivo do resultado primário sobre as expectativas inflacionárias pode ser a percepção de que o governo não conseguirá continuar gerando superávits primários pelo modelo corrente de ajuste fiscal. Dessa forma, o corte dos gastos públicos primários seria relevante para extinguir eventuais dúvidas quanto à sustentabilidade da dívida pública.

Porém, a análise das expectativas fiscais (resultado primário e razão da dívida sobre o PIB) realizada por Pires (2006) mostra que, quando o horizonte de tempo é mais longo, a expectativa de superávit é menor e a expectativa da dívida é também menor, o que poderia contradizer o argumento apresentado. ${ }^{45}$ Essa análise, contudo, carece de maior cuidado. Um ponto interessante é que, quando o horizonte se alonga, o desvio padrão das expectativas fiscais (especialmente da razão da dívida em relação ao PIB) aumenta consideravelmente também, sinalizando uma maior incerteza. ${ }^{46}$

Os resultados da análise de sensibilidade, contudo, mostram alguns períodos em que esse efeito é negativo no período pós-crise, atentando para o fato de que o efeito negativo é consideravelmente maior em magnitude do que o efeito positivo. Uma dúvida que poderia ser resolvida através do cálculo do intervalo de confiança do produto da rede (que foge ao escopo deste trabalho) é se apenas os efeitos negativos são significativos.

A surpresa de curto prazo do IPCA não se mostrou estatisticamente significante a 10\%, ao contrário do que ocorre em Lowenkron e Garcia (2007), em que essa variável impacta o desvio das expectativas em relação à meta. Contudo, o resultado aqui obtido é semelhante ao encontrado por Schmidt-Hebbel e Werner (2002).

Quanto à primeira defasagem das expectativas, o seu efeito positivo aumenta no período de crise e, apesar de diminuir em magnitude no período pós-crise de confiança, permanece em um nível maior que no período anterior à crise. De todas as variáveis, a defasagem de primeira ordem das ex- 
pectativas de inflação é a que apresenta o maior efeito médio sobre as expectativas, evidenciando um forte comportamento adaptativo. $\mathrm{O}$ efeito da defasagem de ordem dois é menor e parece que vem diminuindo no período pós-crise. Dessa forma, o ajustamento das expectativas em função de choques em suas variáveis explicativas se dará de forma gradual.

É interessante notar também que, no período de crise, há uma maior dispersão dos efeitos de cada variável sobre as expectativas de inflação, medida pelos desvios padrão dos efeitos das variações de cada variável em cada período. Isso é um indício de maior incerteza a respeito da inflação futura por parte dos agentes.

Dados os resultados expostos, pode-se concluir que o Banco Central vem consolidando sua credibilidade ao longo do tempo, já que o efeito da meta sobre as expectativas inflacionárias vem crescendo e os efeitos das demais variáveis, diminuindo. Porém, há ainda espaço para melhoria, dado o efeito expressivo de variáveis como a volatilidade cambial e o preço das commodities sobre as expectativas dos agentes, bem como a magnitude do efeito da própria meta.

\section{CONSIDERAÇÕES FINAIS}

O presente trabalho buscou analisar empiricamente os determinantes das expectativas de inflação no Brasil, no período recente (pós-metas de inflação), utilizando para isso os modelos de RNAs, que possuem a característica atraente de reconhecer trajetórias altamente complexas (não lineares) sem que se especifique a forma funcional dessa relação.

O aspecto fundamental do regime de metas de inflação é a coordenação das expectativas dos agentes. Se a autoridade monetária possui credibilidade, as metas de inflação servem como âncora na formação de expectativas. Dessa forma, entender os fatores que afetam tais expectativas é de extrema importância para o adequado direcionamento da política monetária.

De maneira distinta dos trabalhos anteriores que trataram do mesmo assunto, utilizamos os dados das expectativas desagregados por instituição. A principal motivação para o uso do painel de dados foi a reduzida amostra que se teria com os dados agregados. E como bem salientado por Hsiao (2005), a utilização de dados em painel permite uma maior capacidade para 
capturar a complexidade do comportamento humano, quando comparado a séries de tempo ou cross-section simples.

A utilização de RNAs no caso de dados em painel é ainda bastante recente. Alguns poucos trabalhos fizeram uso dessa combinação, a maioria sem nenhum tratamento específico. Desenvolvimentos nessa metodologia podem, no futuro, enriquecer a análise que aqui foi realizada. Uma alternativa bastante interessante para trabalhos futuros é a metodologia de Panel Smooth Transition Regression Models, proposta por González, Teräsvirta e van Dijk (2005). Além disso, um estudo mais cuidadoso do método de inferência aqui adotado, no que se refere à estrutura de dependência dos dados, será bem-vindo. Outra limitação, que pode ser resolvida por trabalhos futuros, é o cálculo do intervalo de confiança para o produto da rede na análise de sensibilidade, o que permitiria verificar se em determinado período a variável deixou de ser significante ou não.

A análise dos dados referentes às expectativas inflacionárias mostra que o erro de previsão vem diminuindo consideravelmente, bem como a incerteza sobre a inflação futura. Esse comportamento parece refletir o forte comprometimento do Banco Central percebido pelos agentes em alcançar a meta de inflação, além de um maior entendimento por parte do mercado da dinâmica da inflação (já que o mercado tem acertado mais no período recente).

Os resultados obtidos aqui permitem afirmar que a maior influência sobre as expectativas inflacionárias no período como um todo foi da volatilidade cambial, seguida pela variação no preço das commodities, pela defasagem de ordem 1 das expectativas, pela variação cambial e pela meta. Em menor magnitude, afetam as expectativas o resultado primário do governo, a defasagem de ordem 2 e a taxa Selic. O comportamento desse efeito ao longo do tempo foi verificado através da análise de sensibilidade do produto da rede em resposta a cada uma das variáveis. No período de crise de confiança, há um expressivo descolamento das expectativas em relação à meta, com um aumento do efeito das demais variáveis. Resultado contrário ocorre no período pós-crise: o efeito da meta de inflação é maior e das demais variáveis, menor, ainda que em alguns casos expressivos (como da defasagem de ordem 1 e da volatilidade cambial). Isso nos leva a concluir que o Banco Central possui credibilidade e esta vem se consolidando ao longo do tempo, mas que há ainda espaço para melhorias. 


\section{APÊNDICE}

\section{Expectativas Fiscais}

Gráfico A.1: Expectativas para o resultado primário do governo, fev./2002 a ago./2006
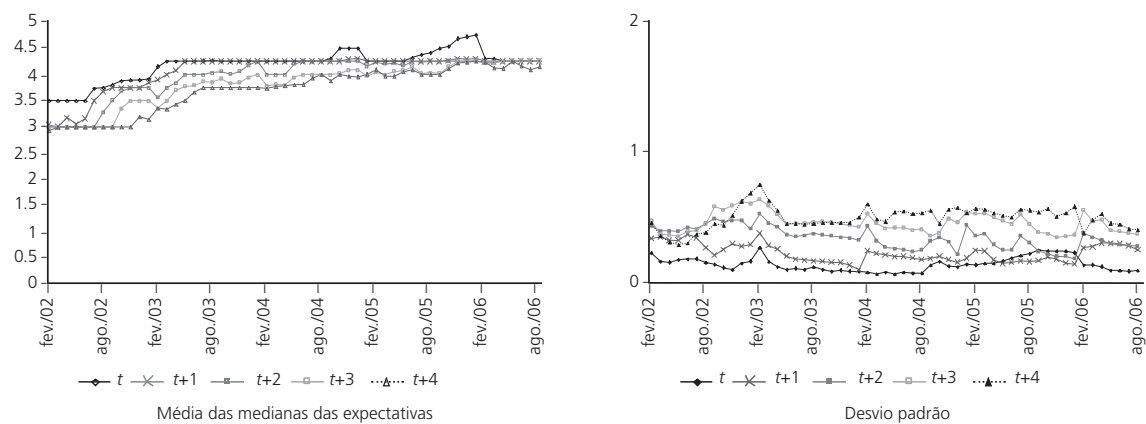

Fonte: Banco Central do Brasil.

Gráfico A.2: Expectativas para a dívida líquida do setor público, fev./2002 a ago./2006
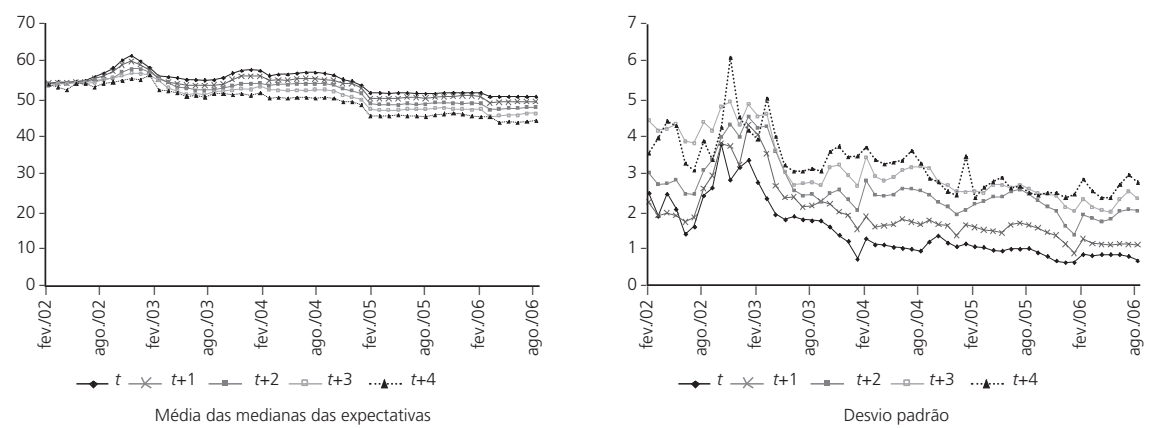

Fonte: Banco Central do Brasil. 


\section{NOTAS}

1. Arthur (1997, p. 2), por exemplo, afirma que, se não fosse a necessidade de se fazer previsões para os valores futuros das variáveis econômicas na tomada de decisão dos agentes, a economia se tornaria matemática.

2. Assim, o erro de previsão teria comportamento de ruído branco.

3. Esta é a ideia básica da abordagem da aprendizagem adaptativa para a modelagem da formação de expectativas, na qual os agentes ajustam suas regras de previsão conforme novos dados se tornam disponíveis.

4. Hornik et al. (1989), entre outros, mostram que, dado um número suficiente de neurônios na camada oculta, uma RNA é capaz de aproximar qualquer função do tipo Borelmensurável ao nível de precisão desejado.

5. Cabe salientar, porém, que o mais adequado seria modelar a formação de expectativas de forma individual, visto que também não é apropriado assumir que os agentes interpretem o mundo e formem suas expectativas de forma homogênea. Os agentes dentro dos modelos econômicos são heterogêneos e a suposição do agente representativo vai contra isso (Beltratti, Margarita e Terna, 1996). Além de haver heterogeneidade, há também interação entre os agentes, que poderia ser modelada usando-se algoritmos genéticos. Porém, o interesse deste trabalho é de natureza empírica, e não teórica. Deseja-se apenas entender como as expectativas são formadas de forma "agregada".

6. Deve-se notar que o controle da autoridade monetária sobre as variáveis é imperfeito. Há defasagem temporal entre a alteração no instrumento e o seu impacto na inflação, incertezas sobre a extensão dessa defasagem, além de choques inesperados.

7. Veja Walsh (2003, p. 543).

8. Para mais detalhes a respeito do survey de expectativas de mercado do Banco Central do Brasil, consulte Marques, Fachada e Cavalcanti (2003).

9. Para evitar que esse resultado fosse consequência de correlação entre metas e inflação passada, os autores incluíram também a defasagem da taxa de inflação 12 meses atual na regressão, porém esta não se mostrou estatisticamente significante a 10\%, excluindo essa possibilidade.

10. A série de inflação esperada 12 meses à frente foi construída utilizando-se a mediana das expectativas no último dia de negócios de cada mês, a fim de garantir que os agentes já conheciam a inflação do mês anterior, mas ainda não tinham informação a respeito da inflação do mês atual (Carvalho e Bugarin, 2005, p. 8).

11. O autor utilizou a série suavizada das expectativas.

12. Ou seja, os autores verificaram se a volatilidade da taxa de juros afeta a volatilidade da inflação esperada.

13. De maneira intuitiva, isso pode ser explicado da seguinte forma: se o efeito da surpresa de inflação de curto prazo nas expectativas de inflação 12 meses é causado apenas pela indexação da economia, não existiria razão para um aumento da incerteza caso a economia fosse afetada por um choque de inflação positivo (Lowenkron e Garcia, 2007, p. 9). 
14. O prêmio de risco da inflação é a diferença entre a inflação de mercado (implícita nos ativos financeiros) e a expectativa de inflação dos participantes do mercado.

15. O que não significa que a indexação também seja a causa. O ponto importante é que a falta de credibilidade piora a situação.

16. Extraída de Deboeck (1994, p. 5).

17. Para mais detalhes, consulte Sarle (1994).

18. Para uma exposição detalhada desses métodos, veja Haykin (2001). Algumas variações do método do gradiente descendente visam a aumentar a velocidade de convergência e minimizar a possibilidade de encontrar mínimos locais.

19. Ver equação 1 .

20. Os subscritos das variáveis de entrada (variáveis explicativas) e produto (variável dependente) foram omitidos para não carregar a notação.

21. Se $Z \sim N(\mu, V)$, então a forma quadrática $Z$ 'KZ $\sim N_{2}(\mu, V ; K)$. A distribuição $\chi^{2}$ é, portanto, um caso particular da distribuição $\mathrm{N}_{2}$ (White, 1994, p. 170).

22. É um tipo de independência assintótica. Assim, embora exista uma dependência entre eventos recentes, quando separados por um grande intervalo de tempo eles são quase independentes. Veja Spanos (1986).

23. A data crítica para o IPCA consiste na data de divulgação do IPCA-15. A data de referência refere-se ao dia anterior à data crítica e é a data-base para a verificação das instituições TOP-5.

24. Gerência Executiva de Relacionamento com Investidores do Banco Central do Brasil.

25. Provocada pelo baixo crescimento mundial, surgimento de problemas contábeis em grandes empresas americanas, crises em mercados emergentes e a perspectiva de mais uma guerra do Golfo.

26. A crise de confiança foi ocasionada pela incerteza em relação às eleições presidenciais, que apontavam o candidato Luiz Inácio Lula da Silva como o favorito, o qual, em seu passado, havia defendido o não pagamento da dívida.

27. Para uma avaliação do período de metas de inflação no Brasil, consulte Garcia (2006) e Bevilaqua et al. (2007).

28. Com a inclusão dessa variável, a amostra diminui expressivamente.

29. Como bem salientado por Bevilaqua et al. (2007), dois problemas com o uso dessa variável no presente caso são a utilização de dados revisados e a aplicação do filtro HP à série da produção industrial completa.

30. As metas de inflação foram ajustadas nos períodos em que o Bacen alterou formalmente a meta a ser perseguida, devido à ocorrência de choques adversos.

31. A medida de relevância sugerida por La Rocca e Perna (2005) é a estatística $m$ dada por: $m=\sum_{t=1}^{n} f_{i}^{2}(x, w)$

32. Existem, porém, trabalhos mostrando os benefícios de se utilizarem duas camadas ocultas. Veja, por exemplo, Barron (1994). 
33. Existem também algumas "regras de bolso" para a determinação desse parâmetro. Porém, como salientado por Zhang et al. (1998, p. 44), nenhuma delas trabalha bem para todos os problemas.

34. O reinício aleatório dos pesos é recomendável, já que o treinamento de uma RNA é bastante sensível aos pesos iniciais. Têm sido propostos, também, alguns métodos para a inicialização dos pesos, como, por exemplo, inicialização baseada nos resultados de uma regressão múltipla (Chan, Lam e Wong, 2000), entre outros.

35. Como salientam Zhang et al. (1998, p. 47) e Swingler (1996, p. 62), a utilização da função logística nos neurônios ocultos é a mais popular escolha para aplicações de RNAs.

36. Aqui cabe uma ressalva: a palavra normalização, na terminologia de RNAs, é utilizada como sinônimo de transformação dos dados originais, de uma maneira que facilite a detecção de características dos dados de entrada.

37. Normalização linear: $\frac{y_{t}-y_{\text {mínimo }}}{y_{\text {máximo }}-y_{\text {minimo }}}$; normalização estatística $\frac{y_{t}-\bar{y}}{d p\left(y_{t}\right)}$.

38. Os testes foram realizados considerando a matriz de variáveis explicativas do modelo, e não exclusivamente as defasagens da variável dependente (como é mais comum em um contexto de séries temporais).

39. Os resultados dessas tentativas podem ser obtidos através de solicitação aos autores.

40. O procedimento de boostrap foi realizado com 500 repetições.

41. Seria interessante obter os intervalos de confiança para o produto da rede para verificar se em alguns períodos as variáveis deixam de ser significativas. Porém, isso foge ao escopo deste trabalho.

42. Repasse das variações cambiais à inflação. As desvalorizações cambiais afetam diretamente a inflação através dos produtos domésticos que utilizam insumos importados e através dos insumos importados que entram no cálculo dos índices de preços e indiretamente por seus efeitos sobre a demanda agregada.

43. Minella et al. $(2002,2003)$ utilizaram a variação cambial acumulada em 12 meses.

44. Ou seja, a redução no risco de default apreciaria o câmbio, levando a uma diminuição das expectativas.

45. Já que significaria que os agentes esperam esforços menores do ponto de vista fiscal, pois estes se tornam menos necessários.

46. Confira os gráficos no Apêndice.

\section{REFERÊNCIAS BIBLIOGRÁFICAS}

ABELÉM, A. J. G. Redes neurais artificiais na previsão de séries temporais. 1994. (Dissertação Mestrado), FEE, PUC, Rio de Janeiro.

ALBUQUERQUE, C. R.; PORTUGAL, M. S. Testing nonlinearities between brazilian exchangerate and inflation volatilities. Revista Brasileira de Economia, v. 60, n. 4, 2006. 
ANDERS, U.; KORN, O. Model selection in neural networks. Neural Networks, v. 12, p. 309-323, 1999.

ANDREWS, D. W. K. Higher order improvements of a computationally attractive k-step bootstrap for extremum estimartors. Econometrica, v. 70, n. 1, p. 119-162, 2002.

ARTHUR, W. B. The end of certainty in Economics. Mathematical Social Sciences, v. 33, n. 1, fev. 1997.

BARRON, A. R. A comment on Neural networks: a review from a statistical perspective. Statistical Science, v. 9, n. 1, p. 33-35, 1994.

BELTRATTI, A.; MARGARITA, S.; TERNA, P. Neural networks for economic and financial modelling. Londres: International Thomson Computer Press, 1996.

BEVILAQUA, A. S.; MESQUITA, M.; MINELLA, A. Brazil: taming inflation expectations. Working Paper Series, Brasília: Banco Central do Brasil, n. 129, p. 1-39, 2007.

CAMPBELL, J. Y.; LO, A. W.; MACKINLAY, A. C. The econometrics of financial markets. [S.l.]: Princeton University Press, 1997.

CARVALHO, F. A. Testing the rationality of market expectations on Brazilian inflation: evidence from an unbalanced panel. Working Paper UNB, Brasília, n. 307, p. 1-24, abr. 2004.

; BUGARIN, M. S. Inflation expectations in Latin América. In: 11th Economía Panel Meeting. Santiago, 2005.

CARVALHO, L. M.; SOUZA JÚNIOR, J. R. de C. Modelo para previsão de inflação. Boletim de Conjuntura IPEA, Rio de Janeiro, n. 72, p. 97-102, 2006.

CERISOLA, M.; GELOS, R. G. What drives inflation expectations in Brazil? An empirical analysis. IMF Working Paper, Washington, n. 05/109, p. 1-22, 2005.

CHAN, M.-C.; LAM, C.-C.; WONG, C.-C. Financial time series forecasting by neural network using conjugate gradient learning algorithm and multiple linear regression weight initialization. Working paper in computing in economics and finance, Society for Computational Economics, n. 61, 2000.

CHENG, B.; TITTERINGTON, D. M. Neural networks: a review from a statistical perspective. Statistical Sciences, v. 9, n. 1, p. 2-54, 1994.

DEBOECK, G. J. Trading on the edge. Nova York: John Wiley \& Sons, 1994.

EVANS, G.; HONKAPOHJA, S. Learning and expectations in macroeconomics. Princeton: Princeton University Press, 2001.

FERNANDES, L. G. L.; PORTUGAL, M.S.; NAVAUX, P. O. A. Previsão de séries de tempo: redes neurais artificiais e modelos estruturais. Pesquisa e Planejamento Econômico, v. 26, n.2, p. 253-276, 1996.

FRANSES, P. H.; VAN DIJK, D. Non-Linear time series models in empirical finance. Cambridge: Cambridge University Press, 2000.

GARCIA, M. G. P. The formation of inflation expectations in Brazil: a study of the futures market for the price level. Revista Brasileira de Economia, v. 48, n. 1, p. 47-70, jan./mar. 1994. 
Inflation Targeting in Brazil: Evaluation and Policy Lessons for Latin American countries. Rio de Janeiro: PUC, 2006.

GONÇALVES, C. E.; GUIMARÃES, B. Monetary policy and the exchange rate in Brazil. In: ENCONTRO BRASILEIRO DE ECONOMETRIA, 28, Anais. Salvador, 2006.

GONZÁLEZ, A.; TERÄSVIRTA, T.; VAN DIJK, D. Panel Smooth Transition Regression Models. Research Paper, Quantitative Finance Research Centre of the University of Technology Sydney, n. 165, p. 1-14, 2005.

GRANGER, C. W. J.; TERÄSVIRTA, T. Modelling nonlinear economic relationships. Oxford: Oxford University Press, 1993.

HAYKIN, S. Redes neurais: princípios e prática. Porto Alegre: Bookman, 2001.

HORNIK, K.; STINCHCOMBE, S. M.; WHITE, H. Multilayer feedforward networks are universal approximators. Neural Networks, v. 2, n. 5, p. 359-366, 1989.

HSIAO, C. Analysis of panel data. Cambridge: Cambridge University Press, 2003.

. Why panel data? IEPR Working Paper, Los Angeles, n. 5-33, p. 1-17, 2005.

KAPETANIOS, G. A bootstrap procedure for panel datasets with many cross-sectional units. Working Papers, Department of Economics of the University of Londres, n. 523, p.1-15, 2004.

KUAN, C. M.; WHITE, H. Artificial neural networks: an econometric perspective. Econometric Reviews, v. 13, n. 1, p. 1-91, 1994.

LAHIRI, S. N. Resampling methods for dependent data. Nova York: Springer, 2003.

LA ROCCA, M.; PERNA, C. Subsampling in artificial neural networks for hydrological data. Metodi statistici e matematici per l'analisi delle serie idrologiche, p. 103-114, 2003. Disponível em: www.irpi.pg.cnr.it/it/grimaldi/papers/LaRoccaPerna2003.pdf

Variable selection in neural network regression models with dependent data: a subsampling approach. Computational Statistics \& Data Analysis, v. 48, p. 415-429, 2005.

LEE, T.H.; WHITE, H.; GRANGER, C. W. J. Testing for neglected nonlinearity in time series models - a comparison of neural network methods and alternative tests. Journal of Econometrics, v. 56, n. 3, p. 269-290, 1993.

LIMA, E. C. R.; CÉSPEDES, B. J. V. O desempenho do Mercado (Focus) e do Bacen na previsão da inflação: comparações com modelos lineares univariados. Boletim de Conjuntura IPEA, Rio de Janeiro, n. 60, p. 75-83, mar. 2003.

LONGHI, S.; NIJKAMP, P.; REGGIANI, A.; MAIERHOFER, E. Neural network modeling as a tool for forecasting regional employment patterns. International Regional Science Review, v. 28, n. 3, p. 330-346, 2005.

LOWENKRON, A.; GARCIA, M. Monetary Policy Credibility and Inflation Risk Premium: a model with application to Brazilian data. Textos para Discussão, Rio de Janeiro: Departamento de Economia PUC-RJ, n. 543, p. 1-21, 2007.

LUCAS, R. E. Econometric Policy Evaluation: a critique. In: CARNEGIE-ROCHESTER Conference Series. The Phillips Curve. Amsterdã: North-Holland, 1976, p. 19-46. 
MACKINNON, J. G. Bootstrap inference in econometrics. Canadian Journal of Economics, v. 35, n. 4, p. 615-645, 2002.

MACNELIS, P. D. Neural networks in finance: gaining predictive edge in the market. Rio de Janeiro: Elsevier, 2005.

MARQUES, A.; FACHADA, J.; CAVALCANTI, D. Sistema Banco Central de Expectativas de Mercado. Notas Técnicas do Banco Central do Brasil, Brasília, n. 36, p. 1-27, 2003.

MEDEIROS, M. C.; TERÄSVIRTA,T.; RECH, G. Building neural network models for time series: a statistical approach. Journal of Forecasting, v. 25, n.1, p. 49-75, 2006.

MELLO, L. M.; MOCCERO, D. Monetary policy and inflation expectations in Latin America: long-run effects and volatility spillovers. OECD Working Paper, n. 518, p. 1-26, 2006.

MINELLA, A.; FREITAS, P.; GOLDFAJN, I.; MUINHOS, M. Inflation Targeting in Brazil: Lessons and Challenges. Working Paper of the Central Bank of Brazil, Brasília, n. 53, 2002.

;_________ Inflation Targeting in Brazil: constructing credibility under exchange rate volatility. Journal of International Money and Finance, v. 22, n.7, p. 1015-1040, 2003.

MISRA, M.; WARNER, B. Understanding neural networks as statistical tools. The American Statistician, v. 50, n. 4, p. 284-293, 1996.

MUTH, J. Rational Expectations and the theory of price movements. Econometrica, v. 29, n. 3, p. 315-335, 1961.

PALMA, A. A.; SARTORIS, A. Inference in Artificial Neural Networks: Testing Market Efficiency for the Brazilian Exchange Rate. Anais do Encontro Latino-Americano de Econometria Lames. Cidade do México, México. 2006.

PAO, H-T; CHIH, Y-Y. Comparison of TSCS regression and neural network models for panel data forecasting: debt policy. Neural Computing \& Applications, Londres, v. 15, n. 2, p. 117-123, 2006.

PASTORE, A. C.; PINOTTI, M. C.; ALMEIDA, L. P. Public debt, exchange rate shocks and inflation targets. Seminário 5 anos de Metas de Inflação, Banco Central do Brasil, 2004. Disponível em: www.bcb.gov.br/Pec/Seminario5Anos/port/pastorePaper.pdf. Acesso em mar. 2007.

PATUELLI, R.; REGIANNI, A.; NIJKAMP, P.; BLIEN, U. New neural network methods for forecasting regional employment: an analysis of German labour markets. Spatial Economic Analysis, v.1, n. 1, p. 7-30, 2006.

PELTONEN, T. A. Are emerging market currency crises predictable? A test. Working Paper Series, European Central Bank, n. 571, p. 1-49, 2006.

PIRES, M. C. C. Credibilidade na política fiscal: uma análise preliminary para o Brasil. Economia Aplicada, São Paulo, v. 10, n. 3, p. 367-375, 2006.

PIZARRO, J.; GUERRERO, E.; GALINDO, P. L. A statistical model selection strategy applied to neural networks. In: EUROPEAN SYMPOSIUM ON ARTIFICIAL NEURAL NETWORKS, $8^{\text {th }}$, 2000, Bruges. Proceedings..., Bruges: D-Facto, 2000, p. 55-60.

PLIKYNAS, D.; AKBAR, Y. Neural network approaches to estimating FDI flows: evidence from East and Central Europe. Eastern European Economics, v. 44, n. 3, p. 29-59, 2006. 
POLITIS, D. N.; ROMANO, J. P.; WOLF, M. Subsampling. Nova York: Springer, 1999.

PORTUGAL, M. S. Rational Expectations and Economic Policy. [S.1.]:University of Warwick, 1988.

- Neural networks versus time series methods: a forecasting exercise. Revista Brasileira de Economia, v. 49, n. 4, p. 611-629, 1995.

RACINE, J. WHITE, H. Statistical inference, the bootstrap, and neural network modeling with application to foreign exchange rates. IEEE Transactions on Neural Networks, v. 12, n. 4, p. 1-19, 2001.

RIPLEY, B. D. Statistical aspects of neural networks. In: BARNDORFF-NIELSEN, O. E.; JENSEN, J.L.; KENDALL, W. S. (Ed.). Networks and chaos-statistical and probabilistic aspects. Londres: Chapman and Hall, 1993. p. 40-123.

SARGENT, T. Bounded Rationality in Macroeconomics. Oxford: Oxford University Press, 1993.

SARLE, W. S. Neural networks and statistical models. Proceedings of the SAS Users Group International Conference, 1994. p. 1528-1550.

SCHMIDT-HEBBEL, K.; WERNER, A. M. Inflation Targeting in Brazil, Chile and Mexico: performance, credibility, and the exchange rate. Central Bank of Chile Working Paper, Santiago, n. 171, p. 1-51, 2002.

SHACHMUROVE, Y. Applying artificial neural networks to business, economics and finance. Penn CARESS Working Paper, Philadelphia, University of Pennsylvania, n. 8, p. 1-47, 2002.

SHANKER, M.; HU, M. Y.; HUNG, M. S. Effect of data standardization on neural network training. Omega, v. 24, n. 4, p. 385-397, 1996.

SPANOS, A. Statistical Foundations of Econometric Modelling. Nova York: Cambridge University Press, 1986.

SWINGLER, K. Applying neural networks: a practical guide. Londres: Academic Press, 1996.

TERÄSVIRTA, T.; LIN, C. F.; GRANGER, C. W. J. Power of the neural network linearity test. Journal of Time Series Analysis, n. 14, p. 209-220, 1993.

THOMAIDIS, N. S; DOUNIAS, G. A comparison of statistical tests for the adequacy of a neural network regression model. Disponível em: http://papers.ssrn.com/sol3/papers. cfm?abstract_id=9578922007.

WALSH, C. E. Monetary theory and policy. Cambridge: The MIT Press, 2003.

WERNECK, R. L. F. Importância da agenda fiscal. In: SEMINÁRIO ANUAL DO BANCO CENTRAL DO BRASIL, 2006, Rio de Janeiro. Disponível em: http://www.bcb.gov.br/Pec/Seminarios/ SemMetInf2006/port/RogerioWerneck.ppt Acesso em mar. 2007.

WHITE, H. Artificial neural networks: approximation and learning theory. Blackwell Publishers, 1992.

Estimation, inference, and specification analysis. Nova York: Cambridge University Press, 1994. 
YOSHIHIRO, S. S. A formação da expectativa inflacionária no regime monetário de metas de inflação e a credibilidade do Banco Central do Brasil. 2005. Dissertação (Mestrado em Economia) - Escola de Economia de São Paulo, Fundação Getulio Vargas, São Paulo, 2005.

ZHANG, G.; HU, M. Y.; PATUWO, B. E. Forecasting with artificial neural networks: the state of the art. International Journal of Forecasting, v. 14, n. 1, p. 35-62, 1998. 